\title{
A nanotwin-based analytical model to predict dynamics in cryogenic orthogonal machining copper
}

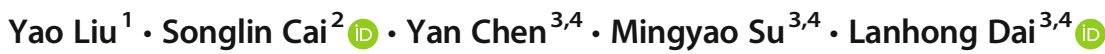

Received: 29 June 2020 / Accepted: 19 October 2020 / Published online: 7 November 2020

(C) Springer-Verlag London Ltd., part of Springer Nature 2020

\begin{abstract}
Cryogenic cooling helps to improve the machining performance and reduce the tool wear. Cryogenic condition could activate these substructures such as deformation twins and dislocation cells. The effects of the substructures are not taken into consideration in the conventional machining models. The conventional models cannot characterize the dynamics in cryogenic machining, i.e., the evolutions of cutting force and temperature with time. Here, considering the effect of the substructures, a new analytical model for metal cutting was proposed to predict the dynamics in cryogenic orthogonal machining. To validate the applicability of the proposed model, the experiments of orthogonal cutting copper at liquid nitrogen temperature and room temperature were conducted. Transmission electron microscope observations show that nanotwins formed in cryogenic cutting copper. The comparisons between experimental cutting forces and the proposed model or the conventional models validate the rationality of the nanotwin-based analytical model. Numerical calculations were further carried out to reveal the underlying mechanism. The periodic oscillation of cutting force in liquid nitrogen condition is a phenomenon of Hopf bifurcation resulting from the formation of nanotwins.
\end{abstract}

Keywords Machining $\cdot$ Orthogonal cutting model $\cdot$ Cryogenic cooling $\cdot$ Hopf bifurcation $\cdot$ Nanotwin

Nomenclature
$t_{0}$
$t_{\mathrm{c}}$
$w$
$\phi$

Supplementary Information The online version contains supplementary material available at https://doi.org/10.1007/s00170-02006303-9.

Songlin Cai

caisonglin@lnm.imech.ac.cn

$\bowtie$ Lanhong Dai

lhdai@lnm.imech.ac.cn

1 School of Mathematics and Physics, University of Science and Technology Beijing, Beijing 100083, People's Republic of China

2 China Electric Power Research Institute, Beijing 100192, People's Republic of China

3 State Key Laboratory of Nonlinear Mechanics, Institute of Mechanics, Chinese Academy of Sciences, Beijing 100190, People's Republic of China

4 School of Engineering Science, University of Chinese Academy of Sciences, Beijing 101408, People's Republic of China

$\begin{array}{ll}V & \text { cutting speed } \\ F_{\mathrm{c}} & \text { cutting force } \\ \rho & \text { mobile dislocation density } \\ t & \text { time } \\ d & \text { mean grain size } \\ \tau_{\mathrm{y}} & \text { shear yield strength } \\ R_{\mathrm{TW}} & \text { mean radius of nanotwin } \\ h_{\mathrm{TW}} & \text { thickness of nanotwin } \\ k_{\mathrm{a}} & \text { annihilation constant } \\ \rho_{0} & \text { initial dislocation density } \\ \gamma_{\mathrm{SF}} & \text { stacking fault energy } \\ b & \text { modulus of Burgers vector } \\ G & \text { shear modulus } \\ T & \text { temperature } \\ \tau & \text { flow shear stress } \\ \widehat{t} & \text { dimensionless time } \\ \widehat{d} & \text { dimensionless grain size } \\ a_{11}(T), a_{12}(T), a_{13}, a_{14}, b_{11}, \text { dimensionless coefficients } \\ b_{12}, b_{13} & \\ f_{\mathrm{nt}} & \text { volume fraction of nanotwin } \\ N_{T W} & \text { concentration of active twins } \\ \eta & \text { fraction of plastically dissipated } \\ & \text { energy }\end{array}$




\begin{tabular}{|c|c|}
\hline$\varepsilon_{\mathrm{D}}$ & $\begin{array}{l}\text { energy of dislocation line per } \\
\text { unit length }\end{array}$ \\
\hline$\Delta$ & mean distance of nanotwins \\
\hline$V_{\mathrm{nt}}$ & speed of nanotwin formation \\
\hline$V_{\mathrm{D}}$ & dislocation motion velocity \\
\hline$n_{0}$ & $\begin{array}{l}\text { total number of twinning } \\
\text { system }\end{array}$ \\
\hline$\rho_{\text {anh }}$ & annihilation rate of dislocation \\
\hline$\tau_{g}$ & $\begin{array}{l}\text { shear yield strength of de- } \\
\text { formed grains }\end{array}$ \\
\hline$\tau_{\mathrm{nt}}$ & $\begin{array}{l}\text { shear yield strength } \\
\text { of nanotwinned grains }\end{array}$ \\
\hline$A_{1}$ & $\begin{array}{l}\text { coefficient } 1 \text { for } \\
\text { deformed grains }\end{array}$ \\
\hline$A_{2}$ & $\begin{array}{l}\text { coefficient } 2 \text { for } \\
\text { deformed grains }\end{array}$ \\
\hline$B_{1}$ & $\begin{array}{l}\text { coefficient } 1 \text { for } \\
\text { nanotwinned grains }\end{array}$ \\
\hline$B_{2}$ & $\begin{array}{l}\text { coefficient } 2 \text { for } \\
\text { nanotwinned grains }\end{array}$ \\
\hline$\tau_{0}$ & $\begin{array}{l}\text { dislocation gliding } \\
\text { frictional stress }\end{array}$ \\
\hline$\alpha$ & dislocation interaction term \\
\hline$k_{\mathrm{TW}}$ & $\begin{array}{l}\text { coefficient of } \\
\text { twinning strengthening }\end{array}$ \\
\hline$\widehat{\tau}$ & dimensionless flow shear stress \\
\hline$\widehat{\rho}$ & $\begin{array}{l}\text { dimensionless } \\
\text { dislocation density }\end{array}$ \\
\hline $\begin{array}{l}\widehat{\rho}^{*} \\
f_{\mathrm{nt}}^{*}\end{array}$ & $\begin{array}{l}\text { equilibrium dislocation density } \\
\text { equilibrium nanotwin volume } \\
\text { fraction }\end{array}$ \\
\hline
\end{tabular}

\section{Introduction}

In machining process, excessive heat due to shearing and friction affects the machined surface quality and cutting tool life $[1,2]$. Lower temperature in cutting zone benefits the metal cutting process. Compared with the machining at ambient temperature, cryogenic cooling could decrease the cutting temperature below the recrystallized temperature of the machining metals [3, 4]. Sharma et al. found that cryogenic cooling could reduce heat at the cutting zone and improve productivity of the process [5]. Some other advantages of cryogenic cooling have been reported, e.g., improving the tool life [6, 7], surface integrity [8-10], and hardness of machined surface [11, 12]. In order to promote the application of cryogenic cooling, Zhang et al. systematically researched the effects of cooling condition on cutting force and tool life during cryogenic milling H13 steel [13]. Recently, a review on cryogenic machining was published to evaluate the effects of cooling fluids on the machining outputs [14]. The experimental researches on cryogenic machining have been widely conducted. However, because of the complicated mechanical behavior at cryogenic machining, the cryogenic machining mechanisms have not been comprehensively understood. Better understanding of the cryogenic machining mechanisms helps to increase the technology readiness level of cryogenic machining and provide a good foundation of cryogenic machining optimization.

The mechanisms of metal cutting have been extensively researched in the past decades. In the 1950s, several classical theoretical models were put forward to characterize the cutting force and shear strain during machining [15]. After that, considerable studies focus on the stability of shear deformation in machining: the onset of serrated chip flow [16-18], the shear banding spacing $[19,20]$, the critical cutting speed for serrated chip [21, 22], the suppression of serrated chip [23, 24], and the sinuous flow $[25,26]$. In recent decade, the effect of material microstructure on the machining theory has attracted intensive scientific interests. The chip formation process was modeled by considering the microstructure of compacted graphite iron [27]. Lee et al. analyzed the effect of crystallographic orientation on shear angle and cutting force by implementing crystal plasticity in the finite element modeling of chip formation [28]. Rahman et al. constructed a flow stress model for metal cutting by correlating the material grain size and chip thickness [29]. An analytical model based on strain-induced martensitic transformation kinetics was developed to predict the microstructural changes in machining austenitic stainless steel [30]. The deformation mechanism of machining single crystals was revealed with the aid of transmission electron microscopy [31]. Recently, Ning and co-workers proposed a series of analytical modeling for ultrafine-grained materials to predict the machining temperatures and forces [32-35]. The above studies focus on the machining mechanisms at room temperature or high temperature; nevertheless, the model for cryogenic machining remained mysterious.

In particular, severe plastic deformation in cryogenic condition could promote the formations of deformation twins and dislocation cells [36], which challenges the previous theory frame. Therefore, it is imperative to establish a new theoretical model considering the effect of deformation twins and dislocation cells. In this work, the experiments of cryogenic orthogonal cutting copper were conducted. Microstructures of chips were characterized by means of electron backscatter diffraction (EBSD) and transmission electron microscope (TEM). Based on the experimental results, a nanotwin-based analytical model was proposed to predict the dynamical behavior in cryogenic orthogonal machining. Using the proposed model, numerical calculations were further carried out to reveal the underlying mechanism of cryogenic orthogonal machining.

\section{Experimental procedure}

Copper with the composition (wt\%): $\mathrm{Cu}(99.95 \%), \mathrm{Fe}$ $(0.004 \%), \mathrm{S}(0.004 \%), \mathrm{Pb}(0.003 \%), \mathrm{Zn}(0.003 \%), \mathrm{Sn}$ 
$(0.002 \%)$, was annealed at $773 \mathrm{~K}$ for $60 \mathrm{~min}$ before machining. As shown in Fig. 1, the initial microstructure of copper is homogeneous coarse grains with few dislocations inside. Referring to ASTM E112 method [37], the grain size is defined by the distance between two adjacent intersection points on the test line segment that crosses the grain at any location due to random placement of the test line. Figure 1a illustrates the definition of grain size. The grain size distribution is shown in Fig. 1c. The average grain size is about $200 \mu \mathrm{m}$. Using the orthogonal cutting equipment in Fig. 2, the copper workpiece was cut at liquid nitrogen temperature. In comparison, cutting copper at room temperature was conducted. The cutting parameters are as follows: the precut thickness of $200 \mu \mathrm{m}$, the chip thickness of $600 \mu \mathrm{m}$, the workpiece thickness of $25 \mathrm{~mm}$, the cutting speed of $2 \mathrm{~mm} / \mathrm{min}$, and the rake angle of $10^{\circ}$. During cutting copper, the cutting force was recorded at the frequency of $30 \mathrm{~Hz}$.

Chips were collected for further microstructural characterization when the processes of cutting copper were finished. Electron backscatter diffraction (EBSD) on chips was conducted by employing JEOL JSM-7800F. Chips were polished down to 2000 grit and then vibratory polish was performed for $8 \mathrm{~h}$. The samples for EBSD were tested by using the following parameters: $15 \mathrm{kV}$ operating voltage and $0.2 \mu \mathrm{m}$ scanning step length. Transmission electron microscope (TEM) was further conducted by using JEM 2010. After polishing down to $\sim 70 \mu \mathrm{m}$, the thin specimens for TEM were obtained in solution with the following composition (vol\%): $\mathrm{H}_{3} \mathrm{PO}_{4}(17 \%), \mathrm{C}_{2} \mathrm{H}_{5} \mathrm{OH}(17 \%), \mathrm{H}_{2} \mathrm{O}(66 \%)$. TEM test was carried out at $200 \mathrm{kV}$ operating voltage. The selected area electron diffraction (SAED) pattern and highresolution TEM images were recorded during TEM observations.

\section{Experimental results}

The cutting forces of orthogonal cutting copper at different temperatures are shown in Fig. 3. Periodic oscillation of cutting force happens during cutting copper at liquid nitrogen temperature. The average amplitude of oscillation is $\sim 1.5$ $\mathrm{kN}$. The average period of oscillation is $\sim 2.5 \mathrm{~s}$. In contrast, the cutting force of orthogonal cutting copper at room temperature is also plotted in Fig. 3. There is no distinct cutting force oscillation for room temperature cutting copper. Experimental results in room temperature machining show that continuous chip can minimize the oscillation in cutting force data $[18,38$, 39]. The chip morphology is continuous in machining copper at the cutting speed of $600 \mathrm{~m} / \mathrm{min}$ [40]. Low cutting speed helps to the formation of continuous chip [20]. Here, the low cutting speed of $2 \mathrm{~mm} / \mathrm{min}$ results in the formation of continuous chip, which explains the minimal oscillation of cutting force in room temperature machining copper. Based on the experimental results [41, 42], the yield strength of copper at liquid nitrogen temperature is higher than that at room temperature. Therefore, the cutting force at liquid nitrogen temperature is larger than that at room temperature.

Figures 4 and 5 show respectively EBSD and TEM images of chips processed by orthogonal cutting copper at different temperatures. Compared with the initial microstructure, grains in chips fragment after orthogonal cutting. As shown in Fig. 4, fragmentation of grains results in the formation of fibershaped grains. The $<111>$ axis of fiber-shaped grains skews the normal direction. The phenomenon of grain fragmentation is similar to that in the experiments of severe plastic deformation [43]. Figure $4 \mathrm{c}$ and f show that the $\{100\}<001>$ texture is distinct in copper chips processed by orthogonal cutting at room temperature or cryogenic temperature. Deformed twins can be formed during orthogonal cutting copper at liquid nitrogen temperature by comparing Fig. 4 a and d. It is illustrated in Fig. 5a, c that high dislocation density could be stored in chips after orthogonal cutting. Similar to the statements [44, 45], the plastic deformation in chip results from the gliding of mobile dislocations. It is indicated in Fig. 5c that nanotwins can be produced during orthogonal cutting copper at liquid nitrogen temperature. The spacing of nanotwin boundary is $\sim 5 \mathrm{~nm}$ from the local magnification in Fig. $5 \mathrm{~d}$.

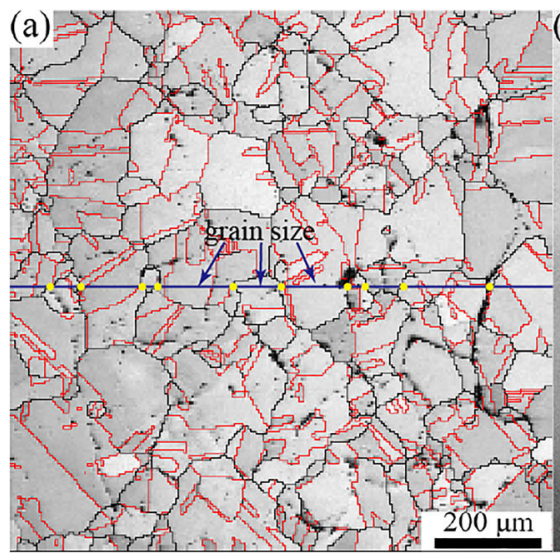

Fig. 1 a EBSD image quality map of initial copper workpiece: grain boundary and twin boundary labeled in black and red respectively. b

(b)

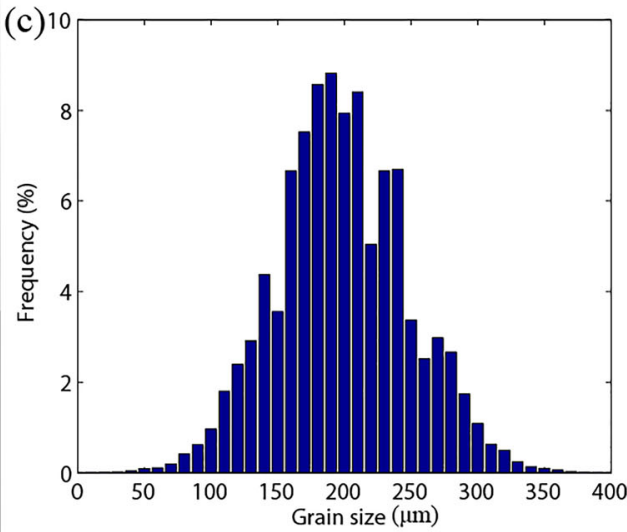

TEM micrograph: the inset showing SAED pattern. c Grain size distribution 

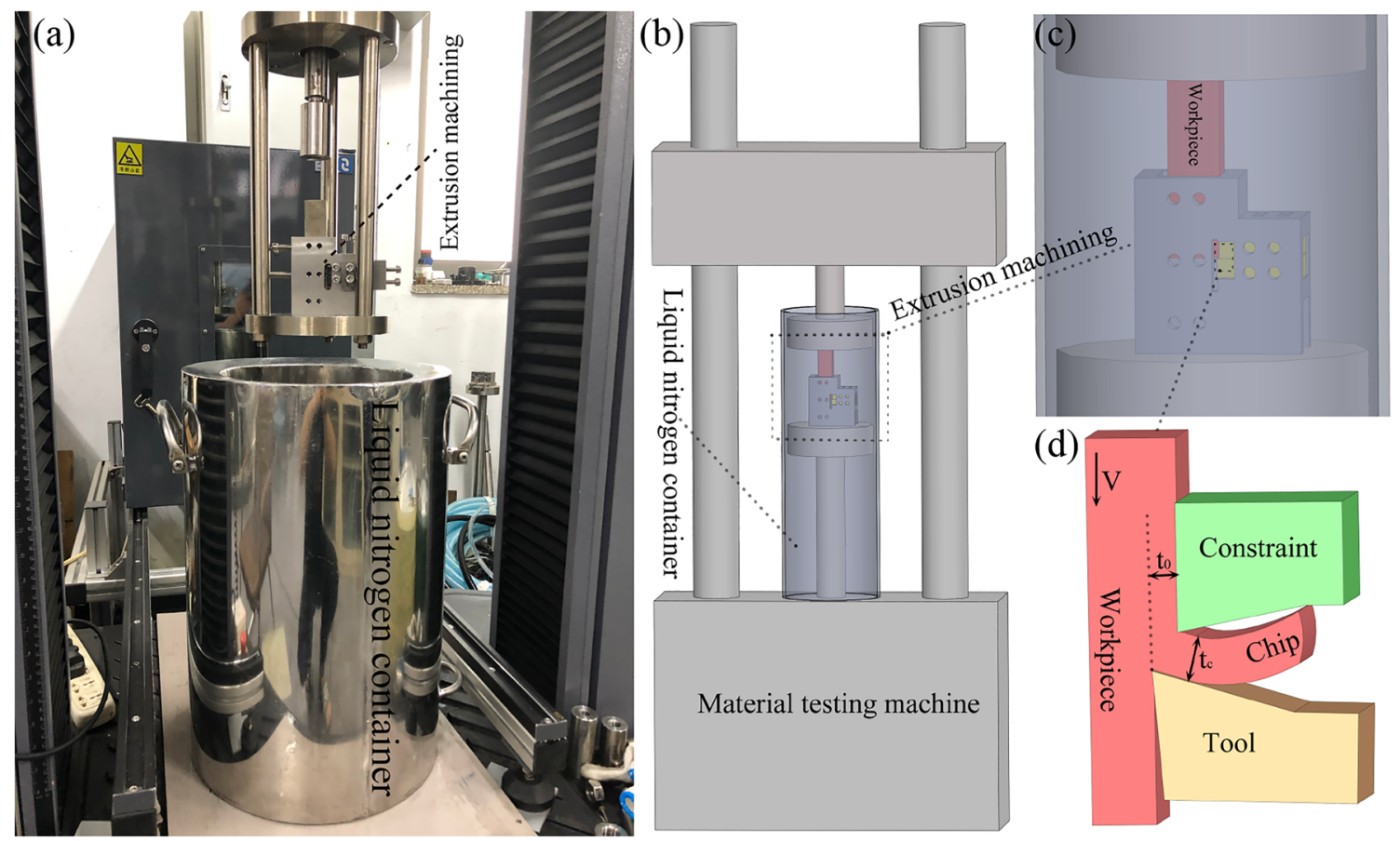

(d)

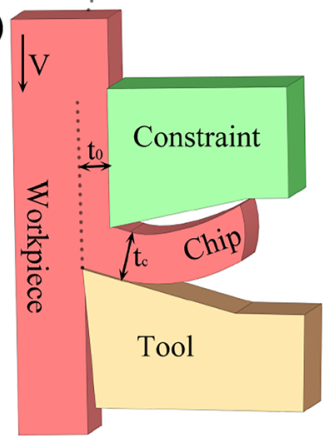

Fig. 2 a Actual experimental setup. b Schematic of orthogonal cutting at cryogen temperature. $\mathbf{c}$ Local magnification of $\mathbf{b}$. d Illustrations of extrusion machining parameters

Fig. 3 Cutting force

measurements during cutting copper at different temperatures: the inset showing the local magnification

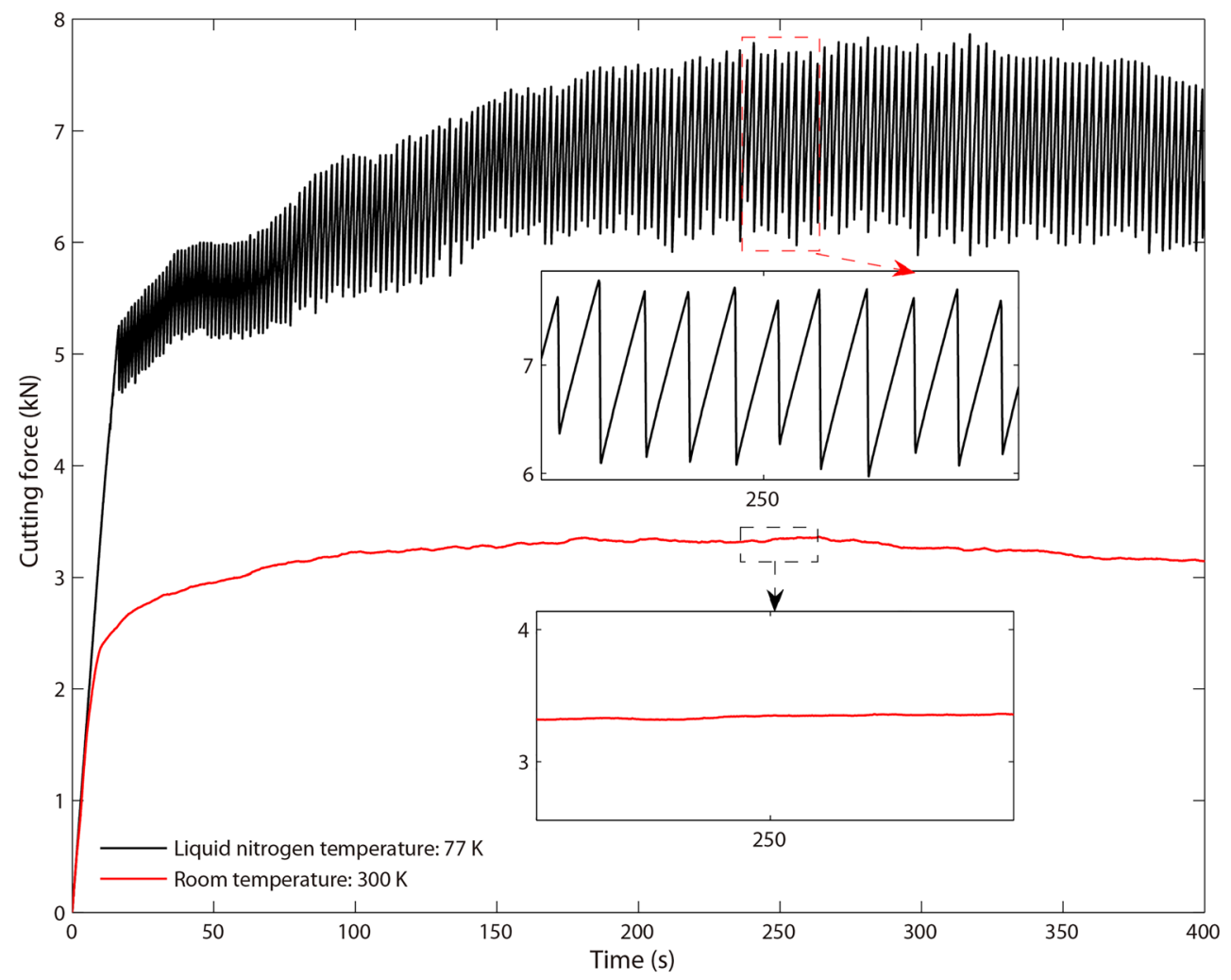



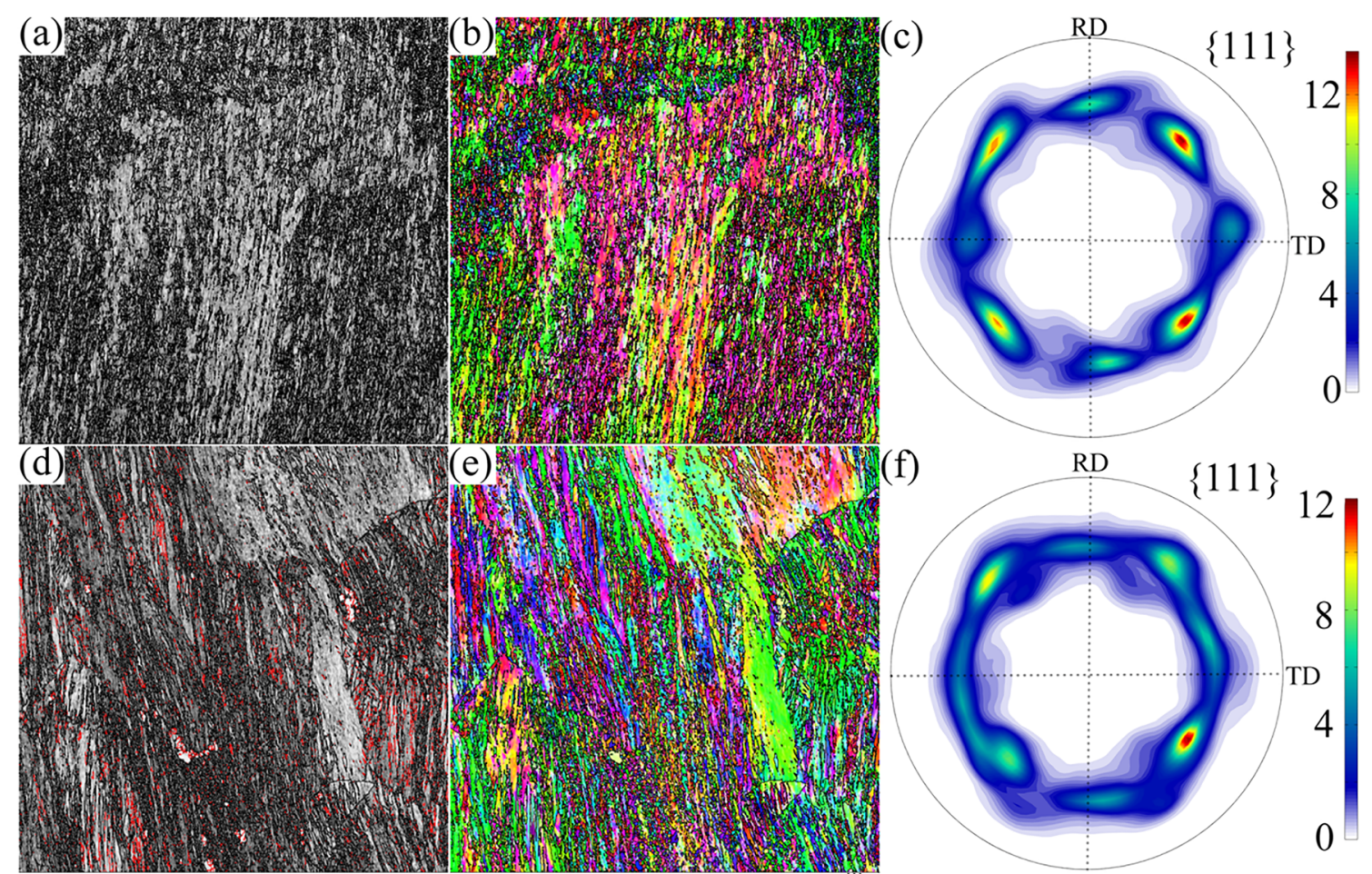

- high angle grain boundary twin boundary
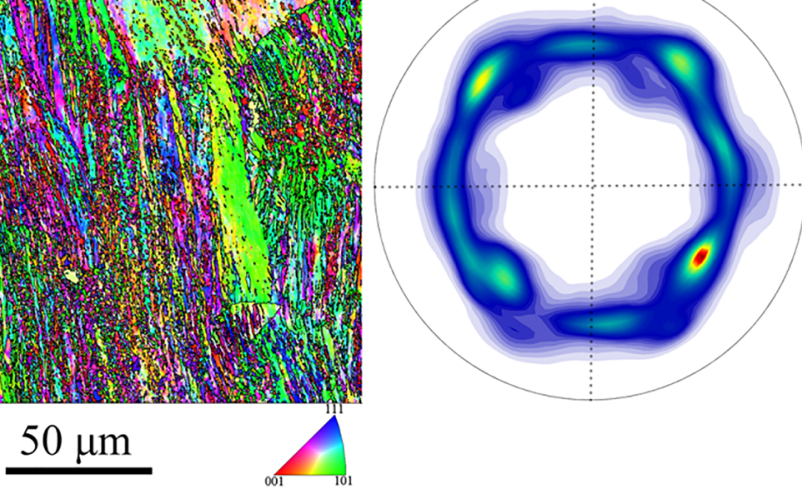

8

0

Fig. 4 EBSD images of chip at room temperature: a image quality map, $\mathbf{b}$ orientation imaging map, $\mathbf{c}$ pole figure. EBSD images of chip at liquid nitrogen temperature: $\mathbf{d}$ image quality map, $\mathbf{e}$ orientation imaging map, $\mathbf{f}$ pole figure

\section{Theoretical model}

\subsection{Governing equations}

According to the conventional models [16, 24], the curve of cutting force should be smooth in the case of $2 \mathrm{~mm} / \mathrm{min}$ cutting speed. However, the experimental results (Figs. 3 and 5) show that the formation of nanotwins leads to the oscillation of cutting force. Because the effect of nanotwins is not taken into consideration in the conventional models, it is improper to use the conventional model for interpreting the experimental results. Thus, a new theoretical model, considering the effect of nanotwins, is needed to characterize the nonlinear dynamics of cryogenic cutting copper.

As illustrated in Fig. 5, mobile dislocations form during machining. Extensive investigations have shown that machining can be treated as plane shear stress state [15]. The mobile dislocation density in machining can be calculated by the following kinetics equations [46]:

$\frac{d \rho}{d t}=\frac{\eta \rho_{0} V_{D} b}{\varepsilon_{\mathrm{D}}} \tau_{y}-\frac{V_{D}}{d} \rho-k_{\mathrm{a}} V_{D} b\left(f_{n t} \rho\right)$.

In Eq. (1), $\rho, t, \tau_{\mathrm{y}}$, and $f_{\text {nt }}$ are mobile dislocation density, time, shear yield strength, and nanotwin volume fraction respectively. $\eta$ is the fraction of plastically dissipated energy because of dislocation motion. $\rho_{0}$ is the initial dislocation density in copper workpiece. $V_{\mathrm{D}}$ is the velocity of dislocation motion. $b$ is the modulus of Burgers vector. $\varepsilon_{\mathrm{D}}$ is the energy of dislocation line per unit length. $d$ is the mean grain size of initial copper workpiece. $k_{\mathrm{a}}$ is annihilation constant.

Here, nanotwins are supposed to be a cylindrical form. The volume fraction of nanotwin $f_{\text {nt }}$ can be simply calculated:

$f_{n t}=\pi R_{T W}^{2} h_{T W} N_{T W}$,

where $R_{\mathrm{TW}}$ is the mean radius, $h_{\mathrm{TW}}$ is the thickness, and $N_{\mathrm{TW}}$ is the concentration of active twins.

The kinetics equation of the concentration of active twins is as follows:

$\frac{d N_{T W}}{d t}=-\left(\frac{1}{\Delta}+\frac{1}{d}\right) V_{n t} N_{T W}+\frac{\varepsilon_{\mathrm{D}} \rho_{a n h}}{\pi R_{T W}^{2} \gamma_{S F} n_{0}}$.

In Eq. (3), $\Delta$ is the mean distance of nanotwins, $V_{\mathrm{nt}}$ is the speed of nanotwin formation, $\gamma_{\mathrm{SF}}$ is the stacking fault energy, and $n_{0}$ is the total number of twinning system. $\rho_{\text {anh }}$ is the annihilation rate of dislocation per unit volume, which can be expressed as:

$\rho_{a n h}=\frac{V_{\mathrm{D}}}{d} \rho+k_{\mathrm{a}} b V_{D} \rho^{2}$.

Substituting Eq. (2) and Eq. (4) into Eq. (3), the evolution of nanotwin volume fraction is in the following form: 
Fig. 5 a TEM micrographs of chip at room temperature (inset showing SAED pattern). b Local magnification of a. $\mathbf{c}$ TEM micrographs of chip at liquid nitrogen temperature (inset showing SAED pattern). d Local magnification of $\mathbf{c}$ $\frac{d f_{\mathrm{nt}}}{d t}=-\left(\frac{1}{\Delta}+\frac{1}{d}\right) V_{n t} f_{n t}+\frac{\varepsilon_{\mathrm{D}} h_{T W} V_{D}}{\gamma_{\mathrm{SF}} n_{0} d} \rho+\frac{\varepsilon_{D} h_{T W} k_{\mathrm{a}} V_{D} b}{\gamma_{\mathrm{SF}} n_{0}}\left(f_{\mathrm{nt}} \rho\right)^{2}$.

Equation (5) indicates three different physical processes affecting the volume fraction of nanotwins: self-diffusion of nanotwins (the first term of the right side), nanotwin generation due to dislocation annihilation (the second term), coupling effect between nanotwin, and dislocation gliding (the third term).

According to microstructural observations in Fig. 5, there are two types of grains in materials: severe plastic deformed grain and nanotwinned grain. The rule-of-mixture equation is used here to characterize shear yield strength $\tau_{\mathrm{y}}$ :

$\tau_{y}=\tau_{g}\left(1-f_{n t}\right)+\tau_{n t} f_{n t}$

where $\tau_{\mathrm{g}}$ and $\tau_{\mathrm{nt}}$ are respectively shear yield strength of severe plastic deformed and nanotwinned grains. A linear relationship between shear yield strength and temperature is used:

$\tau_{g}=A_{1} T+A_{2}$, and

$\tau_{n t}=B_{1} T+B_{2}$

In Eqs. (7) and (8), $T$ is temperature, $A_{1}$ and $A_{2}$ are the coefficients for severe plastic deformed grain, and $B_{1}$ and $B_{2}$ are the coefficients for nanotwinned grain. For severe plastic deformed grains, $A_{2}$ is related with the strain hardening and strain rate hardening, i.e., $A_{2}$ is expressed by:

$A_{2}=\left[A_{21}+A_{22}\left(\frac{\gamma}{\sqrt{3}}\right)^{A_{23}}\right]\left[1+A_{24} \ln \left(\frac{\dot{\gamma}}{\sqrt{3} \dot{\varepsilon_{0}}}\right)\right]$.

In Eq. (9), $A_{21}, A_{22}, A_{23}$, and $A_{24}$ are the coefficients, $\gamma$ is shear strain, $\dot{\gamma}$ is shear strain rate, and $\dot{\varepsilon}_{0}$ is reference strain rate. Shear strain is affected by the depth of cut $[15,47]$. Shear strain rate is calculated by $2 \times 10^{4} \gamma V_{0}[48,49]$ where $V_{0}$ is cutting speed.

According to the microstructures in Fig. 5, an expression considering dislocation density and nanotwin volume fraction is employed for calculating flow shear stress $\tau$. 
$\tau=\tau_{0}+\frac{\alpha G b \sqrt{\rho}}{\sqrt{3}}+\frac{k_{T W} \sqrt{f_{n t}}}{\sqrt{3 h_{T W}\left(1-f_{n t}\right)}}$,

where $\tau_{0}$ is dislocation gliding frictional stress, $\alpha$ is a dislocation interaction term, $G$ is shear modulus, and $k_{\mathrm{TW}}$ is constant coefficient of twinning strengthening.

Concluding the above derivation, the ordinary differential equations (ODEs) for the nanotwin-based analytical model are as follows:

$$
\left\{\begin{array}{l}
\frac{d \rho}{d t}=\frac{\eta \rho_{0} V_{\mathrm{D}} b}{\varepsilon_{\mathrm{D}}}\left[\left(A_{1} T+A_{2}\right)\left(1-f_{\mathrm{nt}}\right)+\left(B_{1} T+B_{2}\right) f_{\mathrm{nt}}\right]-\frac{V_{\mathrm{D}}}{d} \rho-k_{\mathrm{a}} V_{\mathrm{D}} b\left(f_{\mathrm{nt}} \rho\right)^{2} \\
\frac{d f_{\mathrm{nt}}}{d t}=-\left(\frac{1}{\Delta}+\frac{1}{d}\right) V_{\mathrm{n} f} f_{\mathrm{nt}}+\frac{\varepsilon_{\mathrm{D}} h_{\mathrm{TW}} V_{\mathrm{D}}}{\gamma_{\mathrm{SF}} n_{0} d} \rho+\frac{\varepsilon_{\mathrm{D}} h_{\mathrm{TW}} k_{\mathrm{a}} V_{\mathrm{D}} b}{\gamma_{\mathrm{SF}} n_{0}}\left(f_{\mathrm{nt}} \rho\right)^{2} \\
\tau=\tau_{0}+\frac{\alpha G b \sqrt{\rho}}{\sqrt{3}}+\frac{k_{\mathrm{TW}} \sqrt{f_{\mathrm{nt}}}}{\sqrt{3 h_{\mathrm{TW}}\left(1-f_{\mathrm{nt}}\right)}}
\end{array}\right.
$$

The initial conditions for solving Eq. (11) are in the following form:

$\left\{\begin{array}{l}\rho(0)=\rho_{0} \\ f_{\mathrm{nt}}(0)=0\end{array}\right.$

If the values of parameters in Eqs. (11) and (12) are given, the nonlinear dynamics of cryogenic cutting, i.e., the evolutions of dislocation density, nanotwin volume fraction, and flow shear stress, can be calculated. In particular, the presented model is based on the formation of nanotwins. If nanotwins cannot form in the machining materials, Eq. (3) and Eq. (5) cannot be set up. In this case, the presented model may be useless. Therefore, the current work is only useful for predicting the dynamics of machining where the formation of nanotwin is one of deformation modes. Meanwhile, the presented model focuses on the steady-state machining dynamics and it is only capable of prediction under steadystate conditions.

\subsection{Experimental validation}

For face centered cubic (FCC) copper, there are 12 twinning systems, i.e., $n_{0}=12$. The modulus of Burgers vector $b$ is $0.256 \mathrm{~nm}$. The energy of dislocation line per unit length $\varepsilon_{\mathrm{D}} \approx 8 \mathrm{eV} / b$. Based on the experimental results in Fig. 5, the nanotwin thickness $h_{\mathrm{TW}}$ and the mean nanotwin distance are $\sim 5 \mathrm{~nm}$ and $\sim 500 \mathrm{~nm}$ respectively. The mean grain size of $200 \mu \mathrm{m}$ is measured in initial copper workpiece (Fig. 1). The coefficients for Eqs. (7) and (8) are calculated by using the available experimental results $[41,42,50]$. The values for other parameters are referred to the related references.

Substituting the values from Table 1 into Eqs. (11) and (12), the nonlinear dynamics is analyzed. Figure 6 shows the evolutions of dislocation density, nanotwin volume fraction,
Table 1 Values of parameters for copper

\begin{tabular}{|c|c|c|}
\hline Parameters & Value & Reference \\
\hline$n_{0}$ & 12 & Constant \\
\hline$b$ & $0.256 \mathrm{~nm}$ & Literature from [51] \\
\hline$G$ & $42.1 \mathrm{GPa}$ & Idem \\
\hline$d$ & $200 \mu \mathrm{m}$ & Experiments in Fig. 1 \\
\hline$\varepsilon_{\mathrm{D}}$ & $5 \times 10^{-9} \mathrm{~J} / \mathrm{m}$ & Literature from [52] \\
\hline$\eta$ & 0.1 & Idem \\
\hline$\rho_{0}$ & $8 \times 10^{13} \mathrm{~m}^{-2}$ & Literature from [53] \\
\hline$h_{\mathrm{TW}}$ & $5 \mathrm{~nm}$ & Experiments in Fig. 5 \\
\hline$\Delta$ & $500 \mathrm{~nm}$ & Idem \\
\hline$A_{1}$ & $-1.17 \mathrm{MPa} / \mathrm{K}$ & Calculation based on $[40-42,50]$ \\
\hline$A_{21}$ & $175 \mathrm{MPa}$ & Idem \\
\hline$A_{22}$ & $168 \mathrm{MPa}$ & Idem \\
\hline$A_{23}$ & 0.31 & Idem \\
\hline$A_{24}$ & 0.06 & Idem \\
\hline$B_{1}$ & $-0.41 \mathrm{MPa} / \mathrm{K}$ & Idem \\
\hline$B_{2}$ & $424 \mathrm{MPa}$ & Idem \\
\hline$\gamma_{\mathrm{SF}}$ & $45 \mathrm{~mJ} / \mathrm{m}^{2}$ & Literature from [54] \\
\hline$k_{\mathrm{a}}$ & 10 & Literature from [55] \\
\hline$V_{\mathrm{D}}$ & $50 \mu \mathrm{m} / \mathrm{s}$ & Assumption based on [46] \\
\hline$V_{\mathrm{nt}}$ & $9.3 \mu \mathrm{m} / \mathrm{s}$ & Idem \\
\hline$\alpha$ & 0.5 & Literature from [56] \\
\hline$\tau_{0}$ & $17.3 \mathrm{MPa}$ & Literature from [57] \\
\hline$k_{\mathrm{TW}}$ & $1 \times 10^{5} \mathrm{~N} \mathrm{~m}^{-3 / 2}$ & Idem \\
\hline
\end{tabular}

and flow shear stress. The curves for dislocation density, nanotwin volume fraction, and flow shear stress are smooth at room temperature; however, periodic oscillations happen at liquid nitrogen temperature. These tendencies are in good agreement with the experiments in Fig. 3. The calculated nanotwin volume fraction at liquid nitrogen temperature is much larger than that at room temperature, which explains that twin boundary can be easily characterized in Fig. 4. The calculated flow shear stress at liquid nitrogen temperature is higher than that at room temperature, which indicates that smaller cutting force is needed during room temperature cutting (Fig. 3).

The cutting force $F_{\mathrm{c}}$ can be calculated by means of Merchant circle [15]:

$F_{\mathrm{c}}=\frac{\tau t_{0} w}{\sin \phi \cos \phi}$,

where $t_{0}, w$, and $\phi$ are respectively precut thickness, workpiece thickness, and shear angle. Based on the expression [58], the shear angle is calculated $\phi=19.2^{\circ}$.

By means of Eq. (13), the predicted cutting forces are shown in Fig. 7. At the beginning of the cutting process (time $<120 \mathrm{~s}$ ), the deviation between theoretical prediction and 

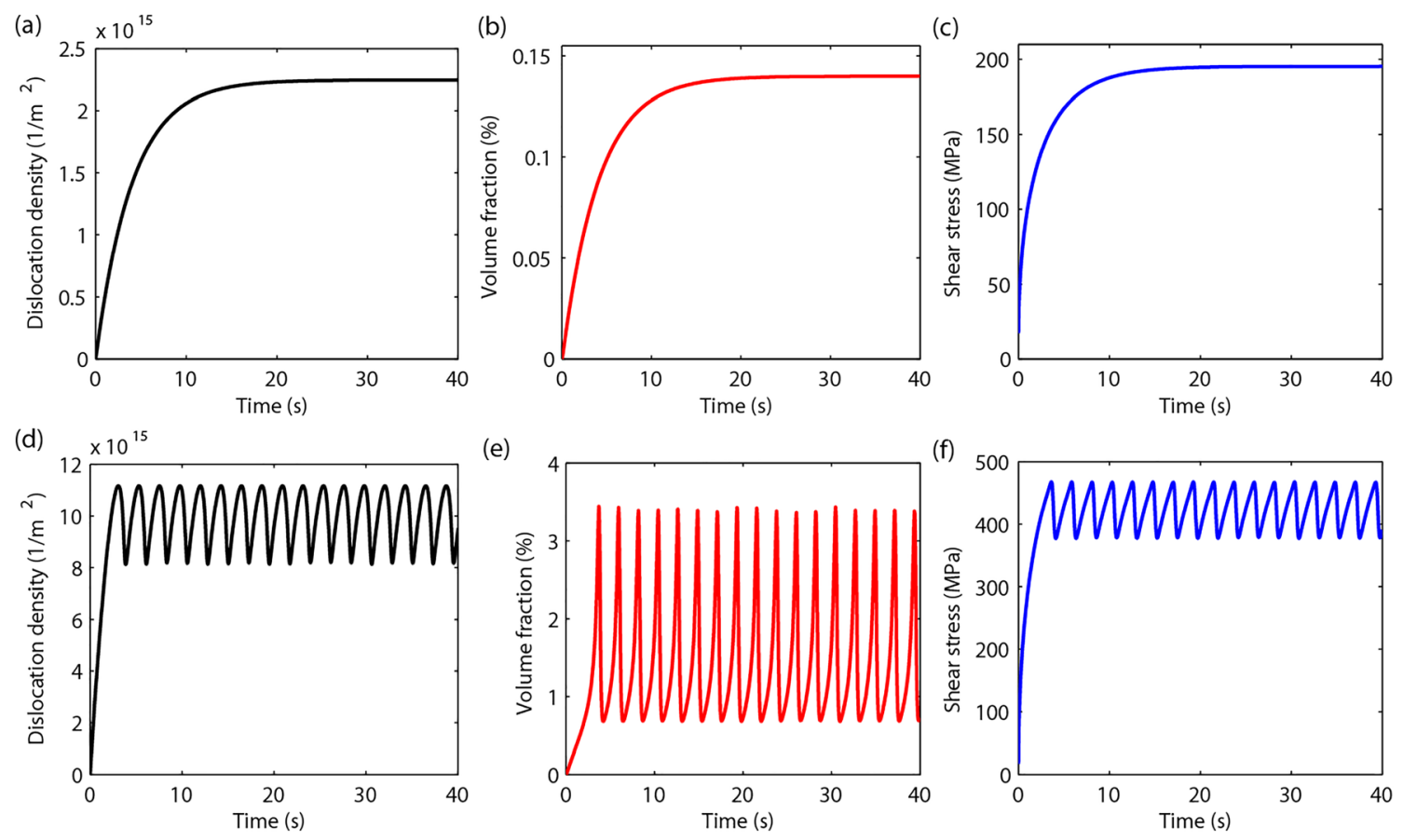

Fig. 6 Evolutions of dislocation density, nanotwin volume fraction and flow shear stress: $\mathbf{a}-\mathbf{c}$ are for orthogonal cutting copper at room temperature; $\mathbf{d}-\mathbf{f}$ are for orthogonal cutting copper at liquid nitrogen temperature

experimental results is more than $15 \%$. Because the proposed model focuses on the steady-state machining dynamics, it failed to predict the cutting forces at the beginning of machining process. As for the steady-state machining, i.e., time $>180$ $\mathrm{s}$, the presented model is accurate to predict the cutting force. For the prediction of crest, the deviation between theory and experiment is $1.1 \%$. The deviation is $1.7 \%$ for the prediction of trough. The predicted cutting force periodically oscillates at liquid nitrogen temperature but is smooth at room temperature. For orthogonal cutting at room temperature, there is no distinct difference of the average cutting force between theoretical prediction and experimental result. As for orthogonal cutting at liquid nitrogen temperature, the amplitude and period predicted by theoretical model capture well the experiments. The proposed model is reasonable to characterize the nonlinear dynamics in cryogenic cutting copper.
Fig. 7 Comparison between theoretical prediction and experimental results at different temperatures

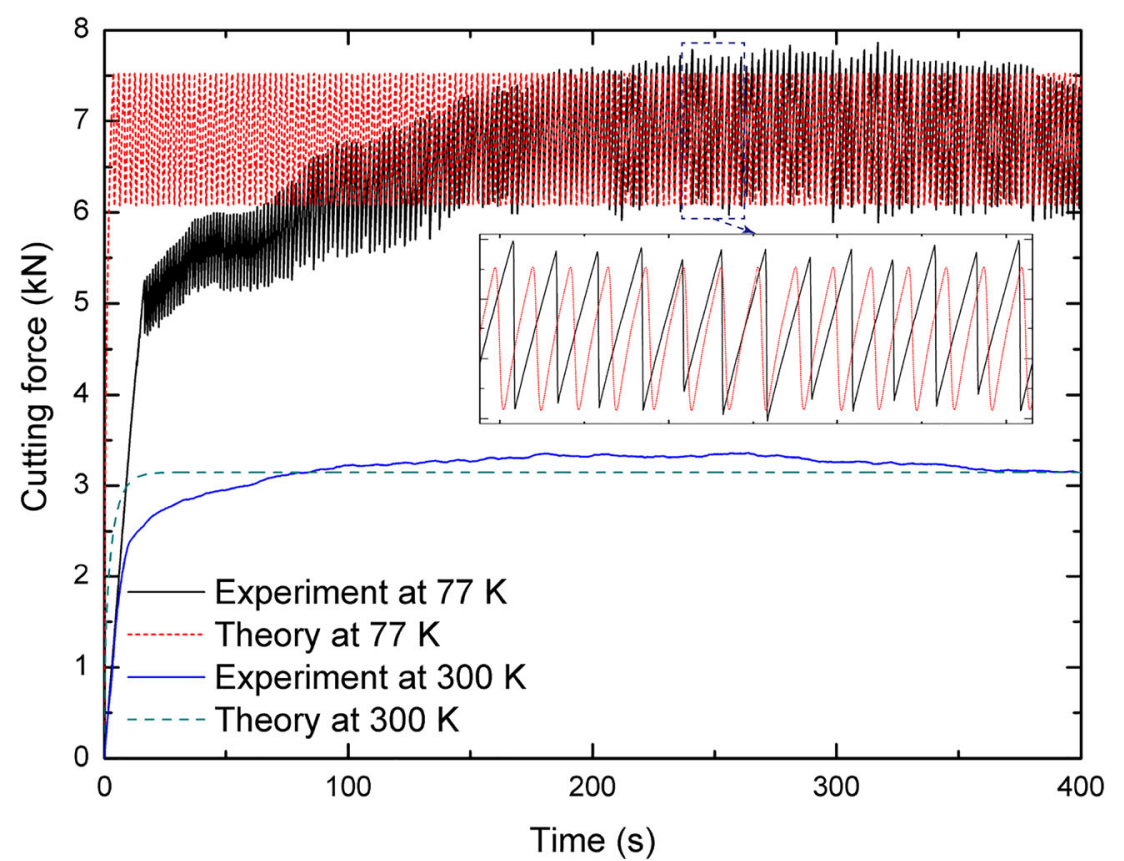




\section{Discussion}

\subsection{Comparison with conventional model}

In order to reveal the feature of the present model, the proposed model is compared with the conventional models. As shown in Fig. 8, in the case of orthogonal cutting copper at liquid nitrogen temperature, shear-band-based model [16] and fracture-based model [24] cannot capture the periodic oscillation of cutting force. Shear-band-based model is based on thermal-plastic instability. It is valid to predict the dynamical behavior of high-speed machining where shear bands emerge periodically. A fracture-based model is put forward by introducing fracture-induced instability. It is rational to characterize the mechanical behavior in low-speed machining where fracture-type segments are dominated deformation pattern. As for machining at liquid nitrogen temperature, formation of nanotwins is an important deformation pattern (Fig. 5c). Because the effect of nanotwins is not taken into consideration in both shear-band-based model and fracture-based model, the two models are useless to predict the dynamical behavior of machining at liquid nitrogen temperature.

\subsection{Hopf bifurcation}

The proposed theory is further employed to reveal the mechanisms underlying orthogonal cutting. According to ODEs (11), orthogonal cutting at different temperatures is a nonlinear autonomous dynamical system. Using the dimensionless variables: $\widehat{\tau}=\frac{\tau}{\tau_{0}}, \widehat{\rho}=\frac{\rho}{\rho_{0}}, \widehat{t}=\sqrt{\rho_{0}} V_{\mathrm{D}} t, \widehat{d}=\sqrt{\rho_{0}} d$, ODEs (11) are transformed into the following non-dimensional equations:

$\left\{\begin{array}{l}\frac{d \widehat{\rho}}{d \widehat{t}}=a_{11}(T)+a_{12}(T) f_{\mathrm{nt}}-a_{13} \widehat{\rho}^{-}-a_{14} f_{\mathrm{nt}}^{2} \widehat{\rho}^{2} \\ \frac{d f_{\mathrm{nt}}}{d \widehat{t}}=-b_{11} f_{\mathrm{nt}}+b_{12} \widehat{\rho}+b_{13} f_{\mathrm{nt}}^{2} \widehat{\rho}^{2}\end{array}\right.$,

where $\widehat{\rho} \geq 1$ and $f_{\text {nt }} \geq 0$. The coefficients in Eq. (14) are as follows:

$\left\{\begin{array}{l}a_{11}(T)=\frac{\eta b\left(A_{1} T+A_{2}\right)}{\varepsilon_{\mathrm{D}} \sqrt{\rho_{0}}} ; a_{12}(T)=\frac{\eta b\left(B_{1} T+B_{2}-A_{1} T-A_{2}\right)}{\varepsilon_{\mathrm{D}} \sqrt{\rho_{0}}} ; a_{13}=\frac{1}{d \sqrt{\rho_{0}}} \\ a_{14}=k_{\mathrm{a}} b \sqrt{\rho_{0}} ; b_{11}=\frac{(\Delta+d) V_{\mathrm{nt}}}{\Delta d V_{\mathrm{D}} \sqrt{\rho_{0}}} ; b_{12}=\frac{\varepsilon_{\mathrm{D}} h_{\mathrm{TW}} \sqrt{\rho_{0}}}{\gamma_{\mathrm{SF}} \eta_{0} d} ; b_{13}=\frac{\varepsilon_{\mathrm{D}} h_{\mathrm{TW}} k_{\mathrm{a}} b \sqrt{\rho_{0}} \rho_{0}}{\gamma_{\mathrm{SF}} n_{0}}\end{array}\right.$.

Here, temperature $T$ is chosen as a bifurcation parameter to discuss the effect of temperature on the nonlinear autonomous dynamical system. Using the values in Table 1, the solutions of Eq. (14) are plotted in Fig. 9. Periodic solutions appear in phase plane at low temperature. The area of solutions decreases with increasing temperature. If temperature exceeds a critical value, the solutions of Eq. (14) converge towards a certain point. As shown in Fig. 9, there is a transition of solution stability. In order to reveal the stability of Eq. (14), the equilibrium point is further calculated. The equilibrium point $\left(\widehat{\rho}^{*}, f_{\mathrm{nt}}^{*}\right)$ for Eq. (14) is determined by:
Fig. 8 Comparisons of different theoretical models for orthogonal machining at liquid nitrogen temperature

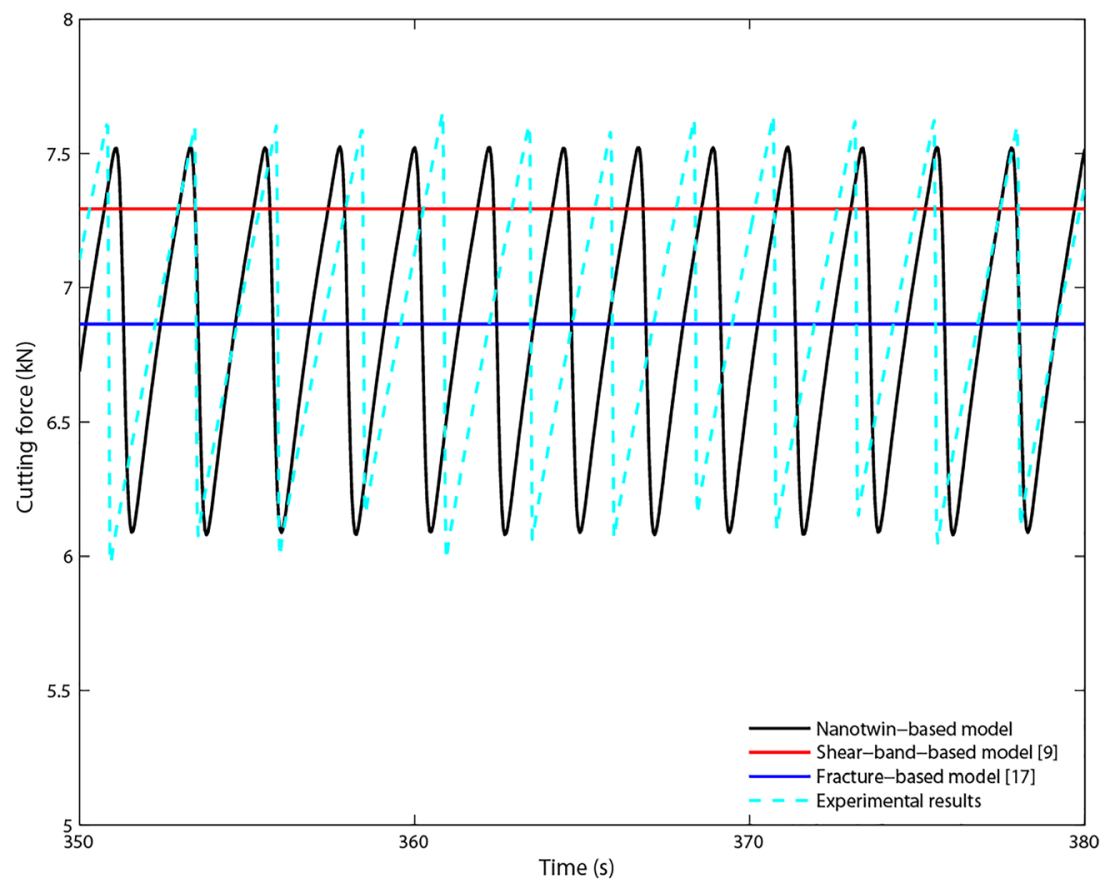


Fig. 9 Solutions of Eq. (14) at different temperatures

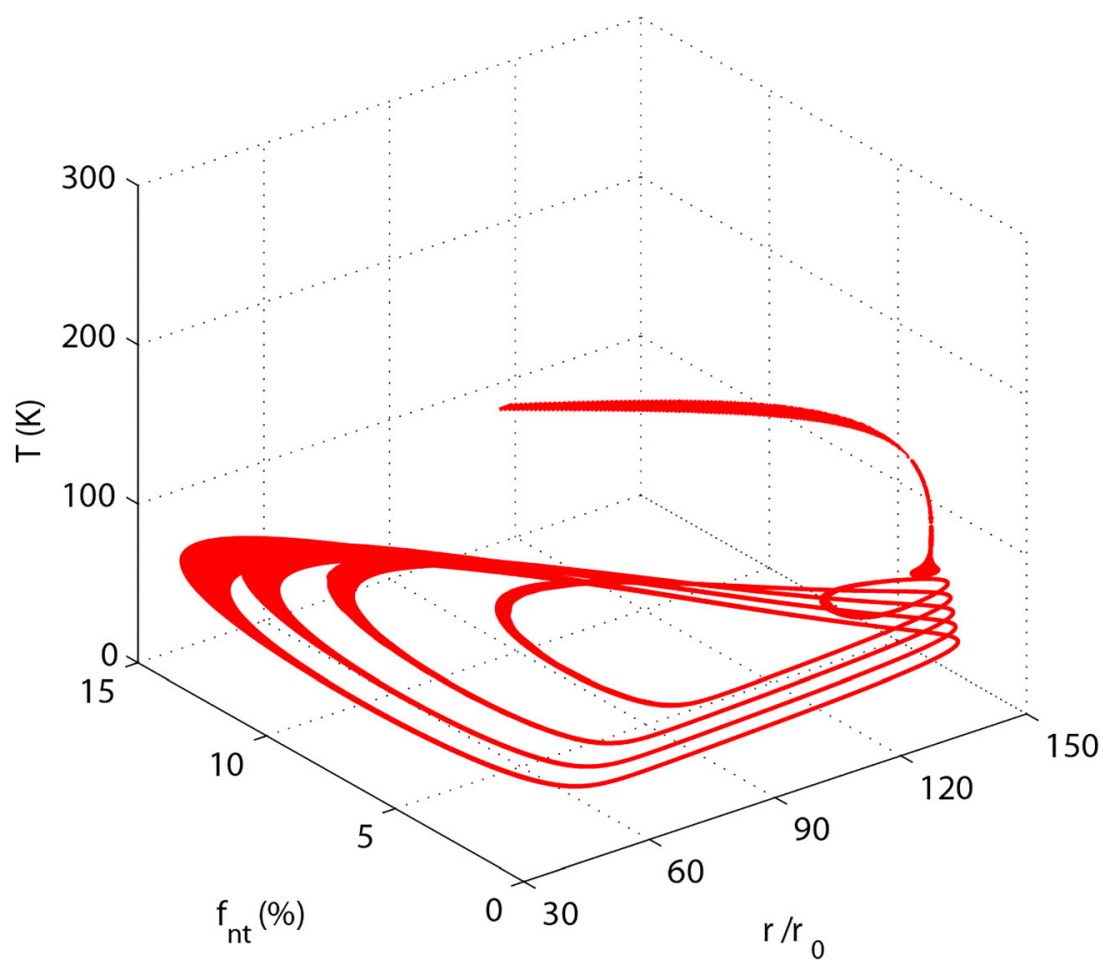

$$
\left\{\begin{array}{l}
a_{11}(T)+a_{12}(T) f_{\mathrm{nt}}^{*}-a_{13} \widehat{\rho}^{*}-a_{14}\left(f_{\mathrm{nt}}^{*} \widehat{\rho}^{*}\right)^{2}=0 \\
-b_{11} f_{\mathrm{nt}}^{*}+b_{12} \widehat{\rho}^{*}+b_{13}\left(f_{\mathrm{nt}}^{*} \widehat{\rho}^{*}\right)^{2}=0
\end{array} .\right.
$$

Solving Eq. (16) in the case of $\widehat{\rho} \geq 1$ and $f_{\text {nt }} \geq 0$, the equilibrium point is given:

$$
\left\{\begin{array}{l}
\widehat{\rho}^{*}=\frac{-b_{12}+\sqrt{b_{12}^{2}+4 b_{11} b_{13}\left(f_{\mathrm{nt}}^{*}\right)^{3}}}{2 b_{13}\left(f_{\mathrm{nt}}^{*}\right)^{2}} . \\
f_{\mathrm{nt}}^{*}=\frac{a_{11} b_{12}}{a_{13} b_{11}-a_{12} b_{12}}
\end{array}\right.
$$

In order to know the stability of Eq. (14), the Jacobian matrix $J$ for Eq. (14) is calculated at equilibrium point:

$$
J=\left[\begin{array}{cc}
-a_{13}-2 a_{14} f_{n t}^{2} \hat{\rho} & a_{12}-2 a_{14} \widehat{\rho}^{2} f_{n t} \\
b_{12}+2 b_{13} f_{n t}^{2} \widehat{\rho} & -b_{11}+2 b_{13} \widehat{\rho}^{2} f_{n t}
\end{array}\right]\left(\hat{\rho}^{*}, f_{n t}^{*}\right) .
$$

The eigenvalues of Jacobian matrix (18) are determined by a second-order eigenvalue equation:

$\lambda^{2}+p \lambda+q=0$,

where the polynomial coefficients are

$$
\left\{\begin{array}{l}
p=a_{13}+b_{11}+2 a_{14}\left(f_{\mathrm{nt}}^{*}\right)^{2} \widehat{\rho}^{*}-2 b_{13} f_{\mathrm{nt}}^{*}\left(\hat{\rho}^{*}\right)^{2} \\
q=a_{13} b_{11}-a_{12} b_{12}+2\left(a_{14} b_{11}-a_{12} b_{13}\right)\left(f_{\mathrm{nt}}^{*}\right)^{2} \widehat{\rho}^{*}+2\left(a_{14} b_{12}-a_{13} b_{13}\right) f_{\mathrm{nt}}^{*}\left(\widehat{\rho}^{*}\right)^{2} .
\end{array}\right.
$$

The stability of Eq. (14) is determined by two eigenvalues $\left(\lambda_{1}, \lambda_{2}\right)$ of Eq. (19).

Lemma 1 If $p^{2}>4 q$, then

When $p>0$ and $q>0$, all roots of Eq. (19) are negative. The equilibrium point of Eq. (14) is stable node. When $p>0$ and $q<0$, all roots of Eq. (19) are positive. The equilibrium point of Eq. (14) is unstable node. When $q<0$, one of the roots of Eq. (19) is negative and the other is positive. The equilibrium point of $\mathrm{E} q$. (14) is saddle-node.

Lemma 2 If $p^{2}<4 q$, then

When $p>0$, all roots of Eq. (19) have negative real parts. The equilibrium point of Eq. (14) is stable focus. When $p<0$, all roots of Eq. (19) have positive real parts. The equilibrium point of Eq. (14) is unstable focus. When $p=0$, Eq. (19) has a pair of purely imaginary roots. The equilibrium point of Eq. (14) is center. 
Lemma 3 If $p^{2}=4 q$, then

When $p>0$, all roots of Eq. (19) are a pair of equal negative real numbers. The equilibrium point of Eq. (14) is stable critical node.

When $p<0$, all roots of Eq. (19) are a pair of equal positive real numbers. The equilibrium point of Eq. (14) is unstable critical node.

When $p=0$, all roots of Eq. (19) are zero. The equilibrium point of Eq. (14) is singularity.

Figure 10 shows the variations of $p, q$, and $p^{2}-4 q$ with increasing temperature. $q$ is always greater than zero if temperature ranges from 0 to $300 \mathrm{~K}$. Both $p$ and $p^{2}-4 q$ increase monotonously with the increasing temperature. As illustrated in the inset of Fig. 10, there are two critical values, i.e., $89 \mathrm{~K}$ and $157 \mathrm{~K}$. If temperature is higher than $89 \mathrm{~K}, p$ is greater than zero; otherwise, $p$ is less than zero. $157 \mathrm{~K}$ is critical temperature to discriminate whether $p^{2}$ is greater than $4 q$. The nonlinear dynamics of the nonlinear autonomous dynamical system is clearly exhibited in Fig. 11 by using Lemmas 1-3. The stability of the solutions depends on the temperature. The temperature range is divided into three parts by two critical temperatures. One of the two critical temperatures is $89 \mathrm{~K}$, where the equilibrium point is center. The other is $157 \mathrm{~K}$ where the equilibrium point is stable critical node. If the temperature is less than $89 \mathrm{~K}$, the solutions with an unstable focus are obtained. In the case of $T>157 \mathrm{~K}$, the solutions of the nonlinear autonomous dynamical system is stable. As for the temperature between $89 \mathrm{~K}$ and $157 \mathrm{~K}$, the equilibrium point is stable focus and the solutions can converge towards a stable limit value.

Substituting the parameter values into Eq. (19), the variation of eigenvalue with increasing temperature is shown in Fig. 12. When the temperature is higher than $157 \mathrm{~K}$, both of eigenvalues are real number. The eigenvalues are less than zero, which indicates stable nonlinear dynamics. If the temperature is less than $89 \mathrm{~K}$, the eigenvalues are conjugate complex numbers. The real part of the conjugate complex numbers is positive; therefore, unstable nonlinear dynamics happens in this case. For the temperature between 89 and $157 \mathrm{~K}$, the eigenvalues with negative real part mean that the deformation in orthogonal cutting is stable. With the decreasing temperature, nonlinear dynamics of orthogonal cutting transforms from stable to unstable. The temperature for this transition is $\sim 89 \mathrm{~K}$.

Figures 13, 14, and 15 show the calculated dynamical behaviors of orthogonal cutting at different temperatures. According to the results in Figs. 13 and 14, dislocation density and nanotwin volume fraction oscillate periodically at cryogenic cutting, and they gradually approach a fixed value with the increasing temperature. Both the period and amplitude decrease with increasing temperature. According to the trajectories in Fig. 15, limit cycle appears in the phase space in cryogenic cutting. Compared with Fig. 15a, higher temperature results in a smaller limit cycle (Fig. 15b). If the deformation temperature exceeds a certain temperature, the trajectory approaches a fixed point (Fig. 15e, f). As for the moderate temperature, the trajectory converges towards a stable limit point (Fig. 15c, d). It is illustrated in Figs. 12 and 15 that there
Fig. 10 Variation of $p, q$, and $p^{2}$ $-4 q$ with the increasing temperature

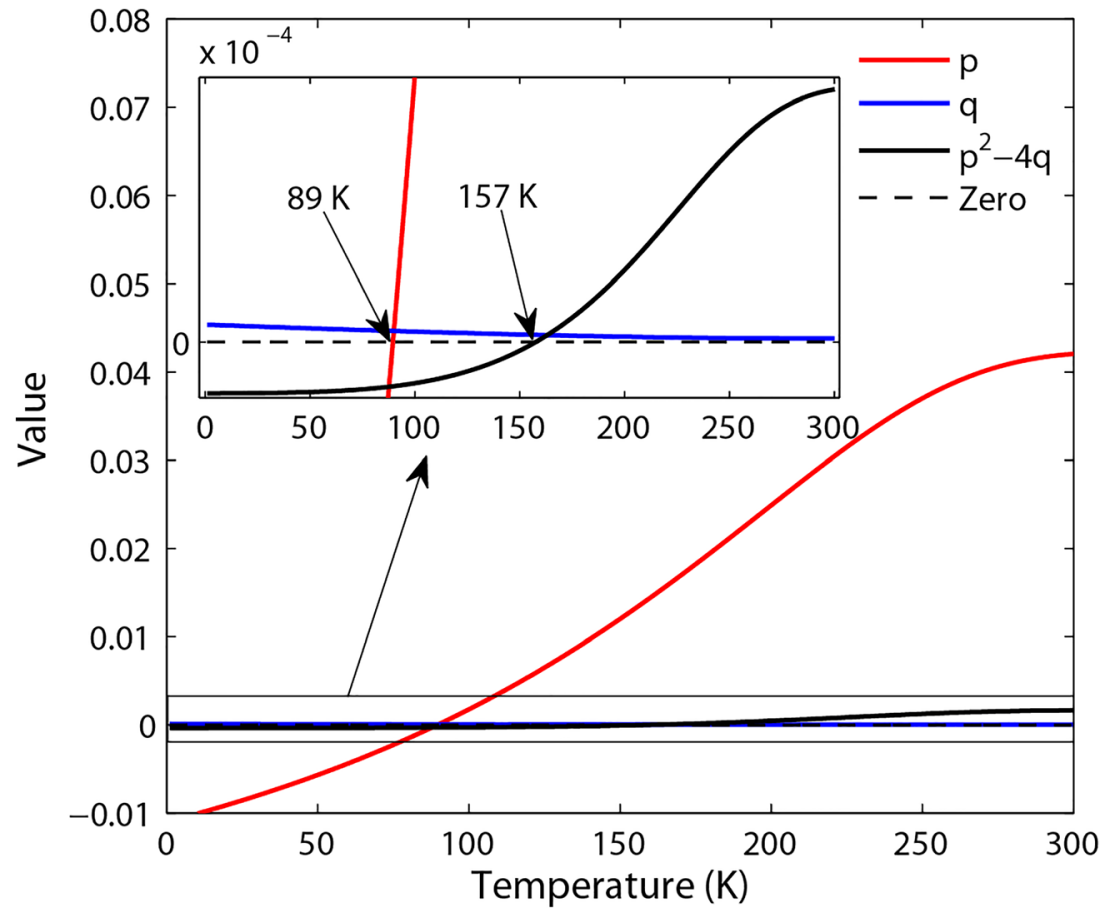




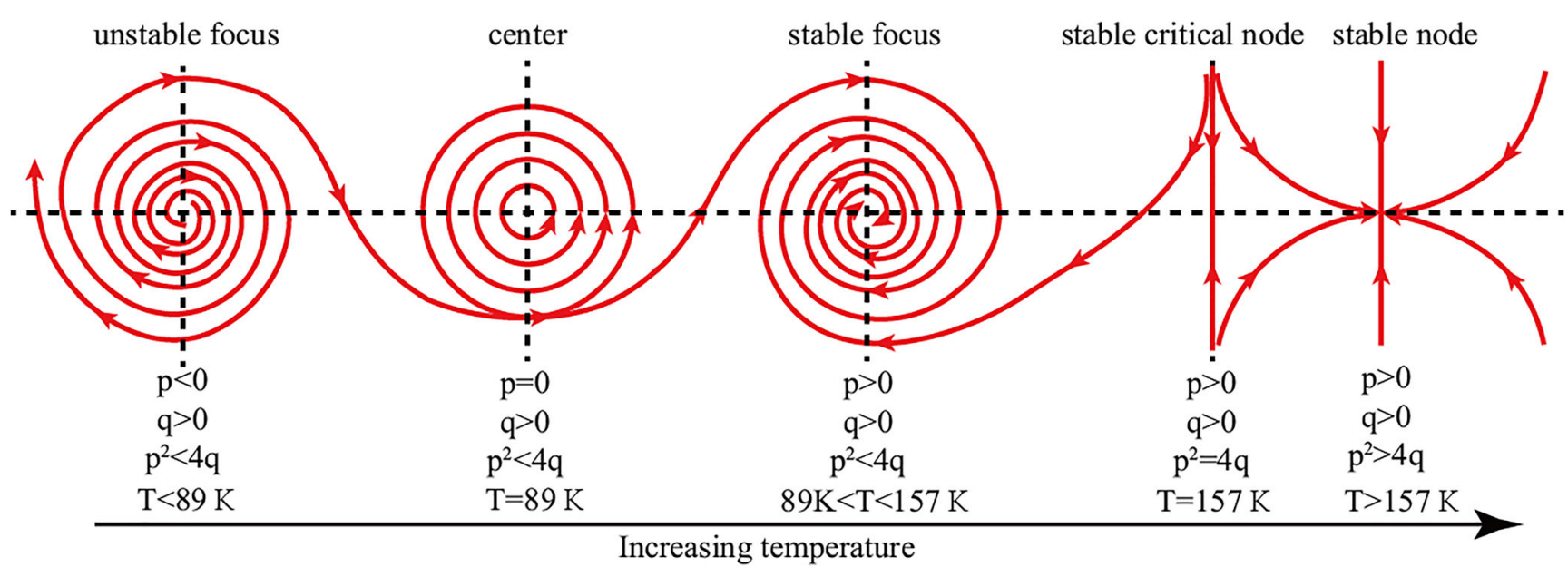

Fig. 11 Stability of solution at different temperatures

are three dynamical behaviors during orthogonal cutting with the increasing temperature. Periodic oscillation and limit cycle happen in the case of the temperature less than $89 \mathrm{~K}$. At the temperature higher than $157 \mathrm{~K}$, steady-state dislocation density and nanotwin volume fraction are achieved. As for temperature between 89 and $157 \mathrm{~K}$, solutions of Eq. (19) are oscillations which decay in amplitude and converge towards a stable limit point.

\subsection{Application conditions}

Combining the experimental results from the literatures [48, $59,60]$ and the presented microstructural observations, the rationality of the presented model is discussed under different cutting conditions. Figure 16 shows the comparisons of experiments and theoretical predictions under different cutting speeds. The comparisons between experimental observations and theoretical results under different cutting depths are illustrated in Fig. 17. It is found from Figs. 16 and 17 that the theoretical predictions are in agreement with the experimental observations; therefore, the proposed model is valid under different cutting speeds and cutting depths.

Compared with the conventional coarse grained materials, nanocrystalline (NC) or ultra-fine-grained (UFG) materials possess much higher strength but poorer ductility [61]. The ductility of NC or UFG materials can be improved by introducing nanotwins (NTs) $[62,63]$. Machining as a method of severe plastic deformation (SPD) has been proved to be an effective technique for producing UFG or NTs in metallic materials $[48,59,60]$. In order to promote the application of
Fig. 12 Variation of eigenvalue with the increasing temperature

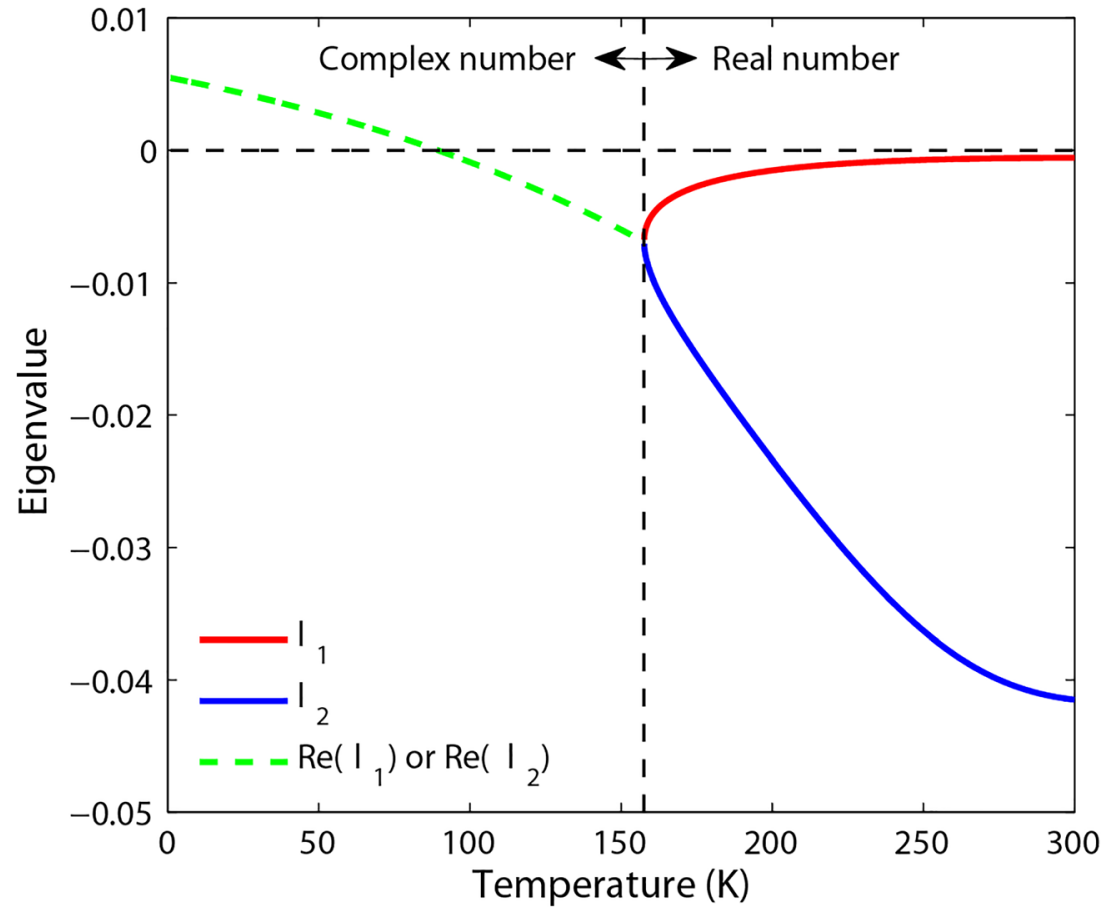



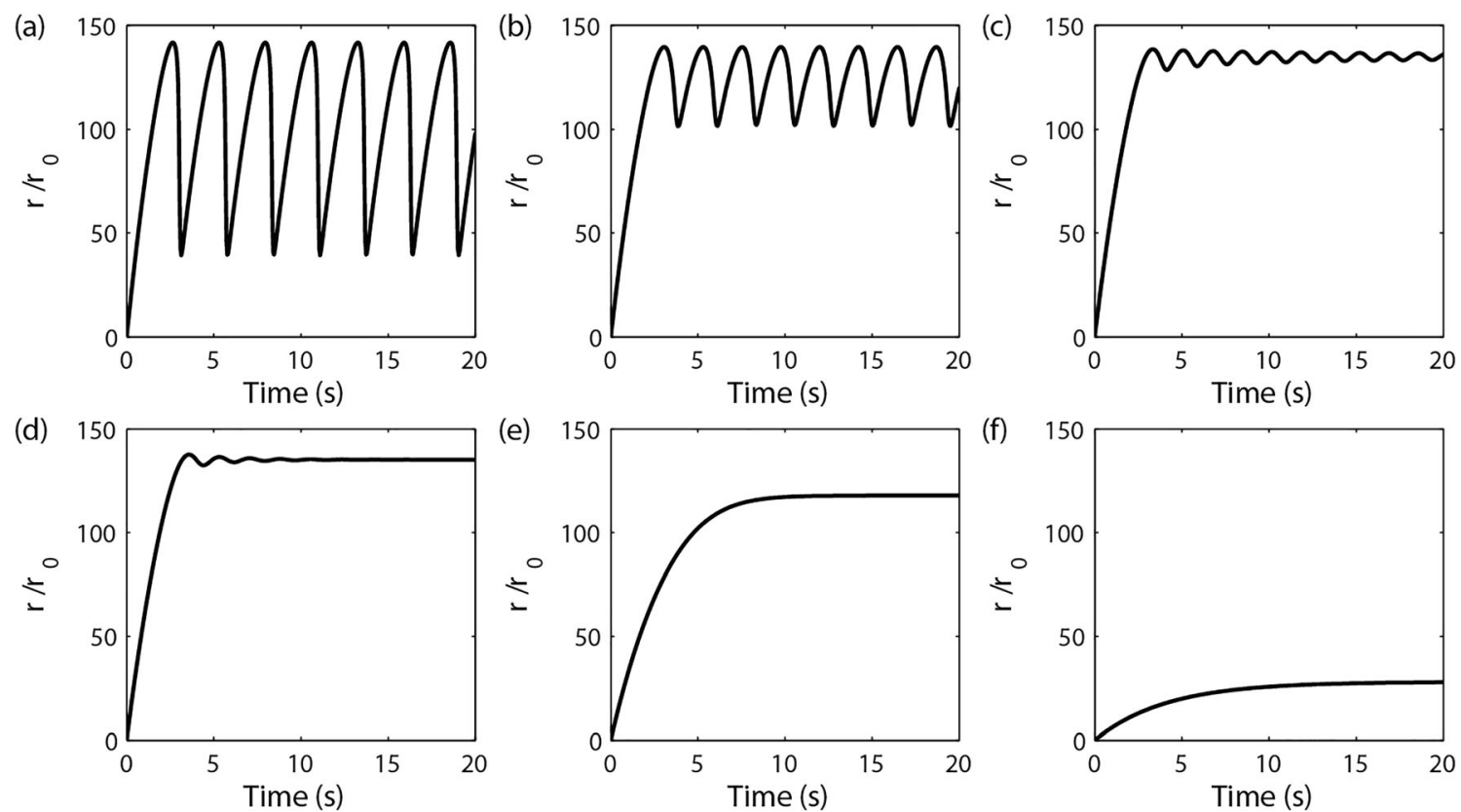

Fig. 13 Evolutions of dislocation density at different temperatures: a $50 \mathrm{~K}, \mathbf{b} 77 \mathrm{~K}$, c $90 \mathrm{~K}$, d $100 \mathrm{~K}$, e $200 \mathrm{~K}$, f $300 \mathrm{~K}$

machining technique in material science, the corresponding theoretical model is required for guiding the selection of machining parameters. The analytical models on machining UFG metals have been built [32-34]. In this work, the analytical model on NT evolution in the machining process was proposed. The proposed analytical model can be used to predict whether NTs could appear in materials under the given cutting conditions. Therefore, the analytical model helps to select suitable machining parameters for NTed material production. In particular, the proposed model is only useful for the machining materials where NT is one of the deformation modes.
In this case, the analytical model can be used for parameter selection during producing NTed materials under the desired cutting conditions.

\section{Concluding remarks}

In this article, cryogenic orthogonal cutting copper and microstructural observations were implemented to comprehensively understand the deformation behavior during cryogenic cutting. The role of temperature was investigated by comparing
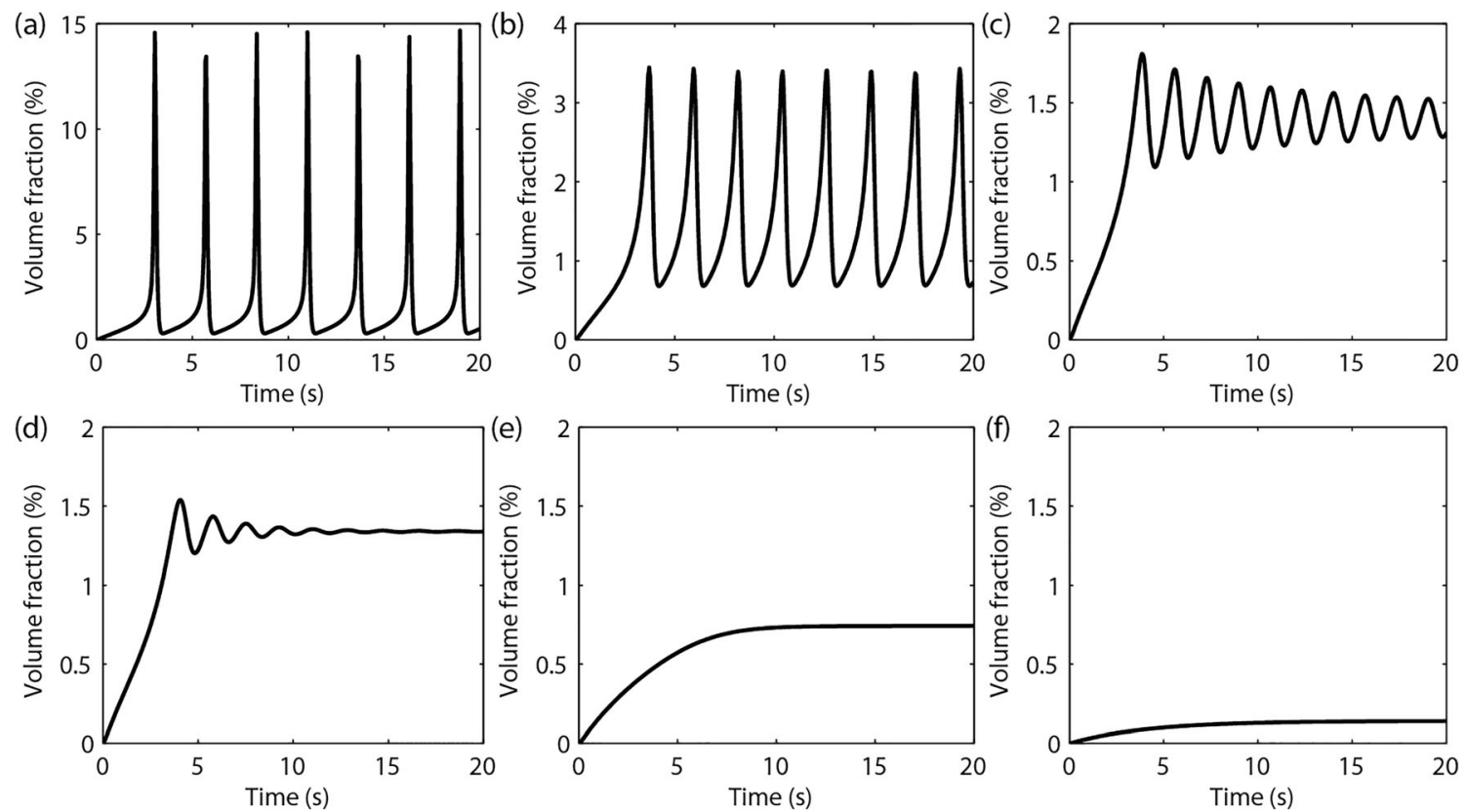

Fig. 14 Evolutions of nanotwin volume fraction at different temperatures: a $50 \mathrm{~K}$, b $77 \mathrm{~K}, \mathbf{c} 90 \mathrm{~K}$, d $100 \mathrm{~K}$, e $200 \mathrm{~K}$, f $300 \mathrm{~K}$ 

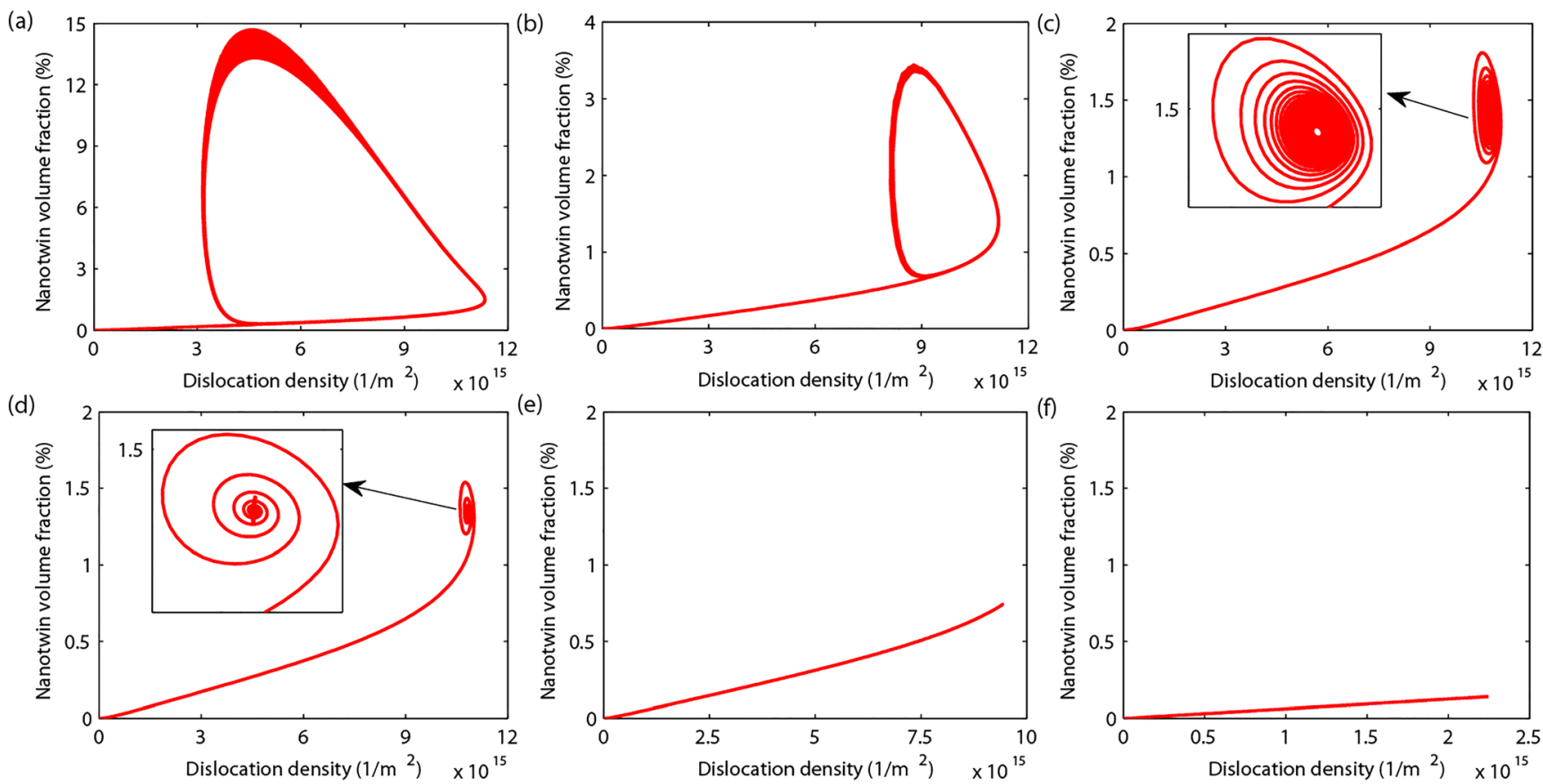

Fig. 15 Trajectories in the phase plane at different temperatures: a $50 \mathrm{~K}$, b $77 \mathrm{~K}, \mathbf{c} 90 \mathrm{~K}$, d $100 \mathrm{~K}$, e $200 \mathrm{~K}$, f $300 \mathrm{~K}$

Fig. 16 Comparisons of experiments and theoretical predictions under different cutting speeds

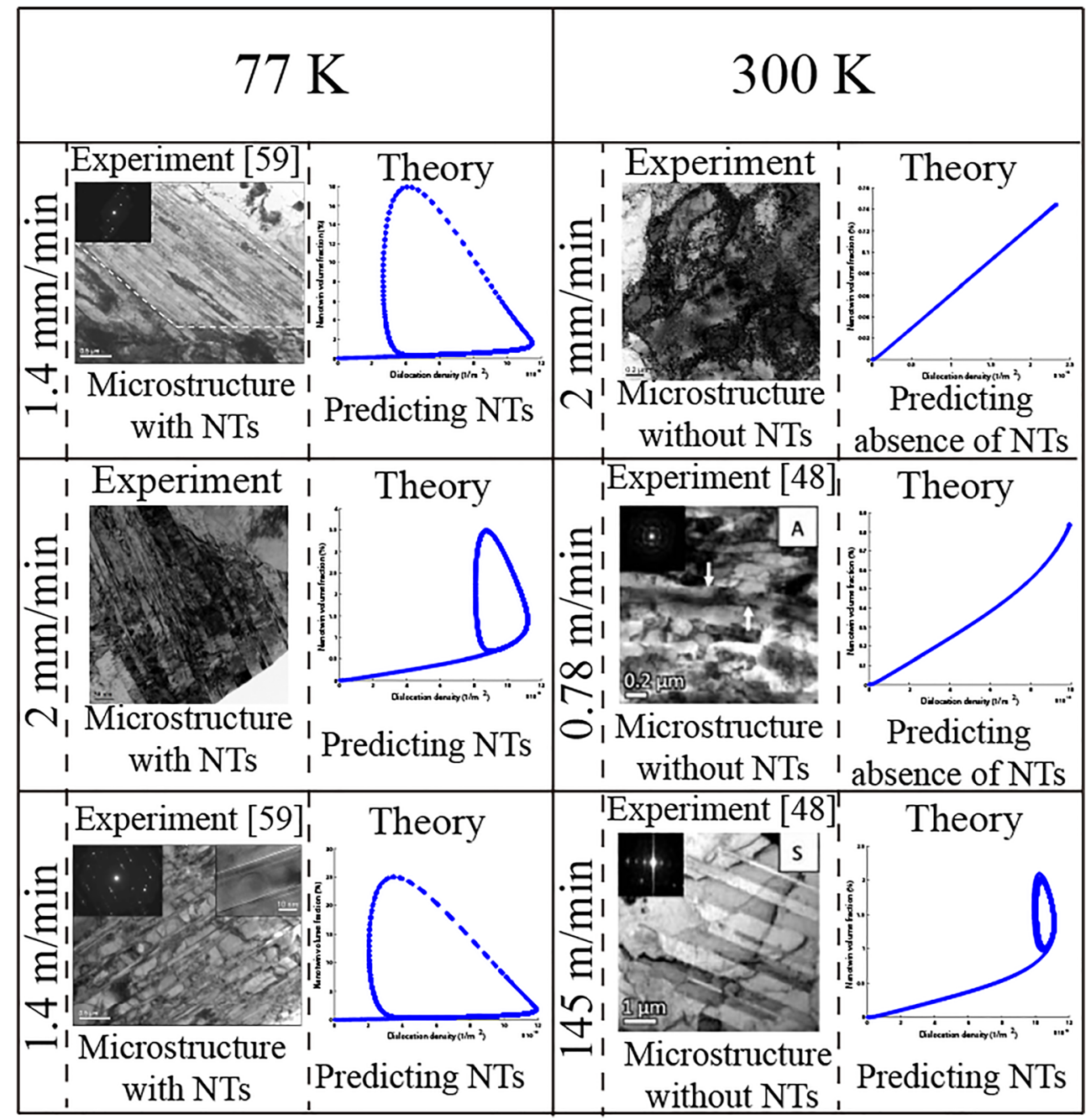


Fig. 17 Comparisons between experimental observations and theoretical results under different cutting depths

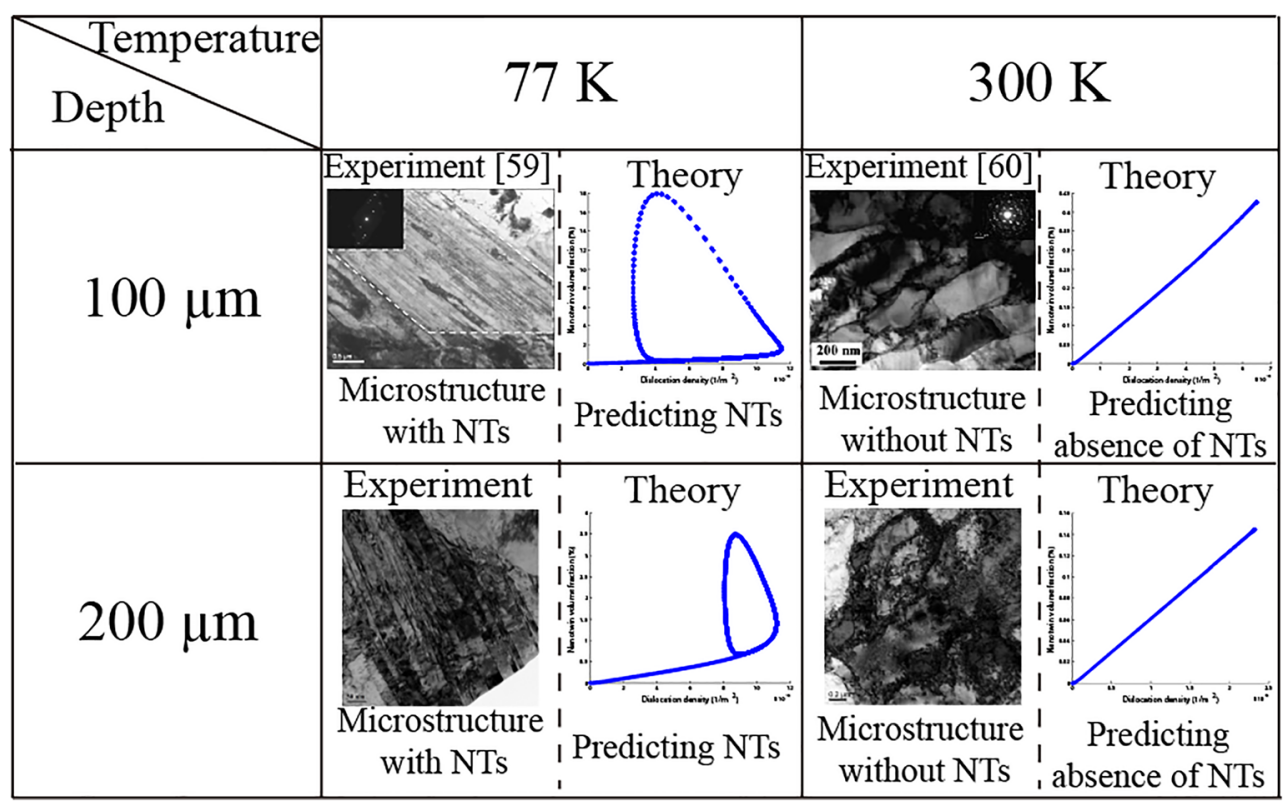

the experimental results and theoretical models. The underlying mechanism in cryogenic cutting was revealed with proper numerical calculations. The following conclusions can be drawn.

(1) Compared with the cutting force in room temperature cutting, periodic oscillation of cutting force happens during cutting copper at liquid nitrogen temperature. Microstrucutral observations illustrate that the formation of nanotwins induces the periodic oscillation of cutting force in cryogenic cutting.

(2) The conventional orthogonal cutting models without considering the effect of nanotwins cannot capture the oscillation of cutting force in cryogenic cutting. A new nanotwin-based analytical model was proposed to predict dynamics in cryogenic orthogonal cutting. The experimental results validate the rationality of the new model. For the prediction of crest, the relative errors of shear-band-based model, fracture-based model, and the new model are respectively $4.1 \%, 9.8 \%$, and $1.1 \%$. For the prediction of trough, the relative errors of shearband-based model, fracture-based model, and the new model are respectively $21.8 \%, 14.7 \%$, and $1.7 \%$.

(3) Based on the proposed model, numerical calculations further reveal that the periodic oscillation of cutting force in cryogenic cutting is a phenomenon of Hopf bifurcation. The explicit formula is derived to determine the stability of the cryogenic cutting. With the decreasing cutting temperature, three distinguished dynamical behaviors are obtained in orthogonal cutting.

Funding This study was funded by the National Key Research and Development Program of China (grant number 2017YFB0702003), the National Natural Science Foundation of China (grant numbers 12072327 and 11802013), Fundamental Research Funds for the Central Universities (grant number FRF-TP-18-020A2), China Scholarship Council (grant number 201909110036), the Strategic Priority Research Program of the Chinese Academy of Sciences (grant numbers XDB22040302 and XDB22040303), and the Key Research Program of Frontier Sciences (grant number QYZDJSSW-JSC011).

\section{Compliance with ethical standards}

Conflict of interest The authors declare that they have no conflict of interest.

\section{References}

1. Yildiz Y, Nalbant M (2008) A review of cryogenic cooling in machining processes. Int J Mach Tools Manuf 48(9):947-964. https://doi.org/10.1016/j.ijmachtools.2008.01.008

2. Sharif MN, Pervaiz S, Deiab I (2017) Potential of alternative lubrication strategies for metal cutting processes: a review. Int J Adv Manuf Technol 89(5):2447-2479. https://doi.org/10.1007/s00170016-9298-5

3. Hong SY, Ding Y (2001) Cooling approaches and cutting temperatures in cryogenic machining of Ti-6Al-4V. Int J Mach Tools Manuf 41(10):1417-1437. https://doi.org/10.1016/S08906955(01)00026-8

4. Danish M, Ginta TL, Habib K, Carou D, Rani AMA, Saha BB (2017) Thermal analysis during turning of AZ31 magnesium alloy under dry and cryogenic conditions. Int J Adv Manuf Technol 91(5):2855-2868. https://doi.org/10.1007/s00170-016-9893-5

5. Sharma VS, Dogra M, Suri NM (2009) Cooling techniques for improved productivity in turning. Int J Mach Tools Manuf 49(6): 435-453. https://doi.org/10.1016/j.ijmachtools.2008.12.010

6. Kaynak Y (2014) Evaluation of machining performance in cryogenic machining of Inconel 718 and comparison with dry and MQL machining. Int J Adv Manuf Technol 72(5):919-933. https://doi. org/10.1007/s00170-014-5683-0

7. Trabelsi S, Morel A, Germain G, Bouaziz Z (2017) Tool wear and cutting forces under cryogenic machining of titanium alloy (Ti17). 
Int J Adv Manuf Technol 91(5):1493-1505. https://doi.org/10. 1007/s00170-016-9841-4

8. Bertolini R, Lizzul L, Pezzato L, Ghiotti A, Bruschi S (2019) Improving surface integrity and corrosion resistance of additive manufactured Ti6Al4V alloy by cryogenic machining. Int J Adv Manuf Technol 104(5):2839-2850. https://doi.org/10.1007/ s00170-019-04180-5

9. Pereira WH, Delijaicov S (2019) Surface integrity of INCONEL 718 turned under cryogenic conditions at high cutting speeds. Int J Adv Manuf Technol 104(5):2163-2177. https://doi.org/10.1007/ s00170-019-03946-1

10. Gong L, Zhao W, Ren F, He N, Li L, Xu Q, Khan AM (2019) Experimental study on surface integrity in cryogenic milling of 35CrMnSiA high-strength steel. Int J Adv Manuf Technol 103(1): 605-615. https://doi.org/10.1007/s00170-019-03577-6

11. Zhao W, Ren F, Iqbal A, Gong L, He N, Xu Q (2020) Effect of liquid nitrogen cooling on surface integrity in cryogenic milling of Ti-6Al-4V titanium alloy. Int J Adv Manuf Technol 106(3):14971508. https://doi.org/10.1007/s00170-019-04721-y

12. Imbrogno S, Rotella G, Rinaldi S (2020) Surface and subsurface modifications of AA7075-T6 induced by dry and cryogenic high speed machining. Int J Adv Manuf Technol 107(1):905-918. https://doi.org/10.1007/s00170-020-05108-0

13. Zhang C, Zhang S, Yan X, Zhang Q (2016) Effects of internal cooling channel structures on cutting forces and tool life in side milling of $\mathrm{H} 13$ steel under cryogenic minimum quantity lubrication condition. Int J Adv Manuf Technol 83(5):975-984. https://doi.org/ 10.1007/s00170-015-7644-7

14. Abdelrazek AH, Choudhury IA, Nukman Y, Kazi SN (2020) Metal cutting lubricants and cutting tools: a review on the performance improvement and sustainability assessment. Int $\mathrm{J}$ Adv Manuf Technol 106(9):4221-4245. https://doi.org/10.1007/s00170-01904890-w

15. Merchant ME (1945) Mechanics of the metal cutting process. I. Orthogonal cutting and a type 2 chip. J Appl Phys 16(5):267-275

16. Burns TJ, Davies MA (1997) Nonlinear dynamics model for chip segmentation in machining. Phys Rev Lett 79(3):447-450. https:// doi.org/10.1103/PhysRevLett.79.447

17. Ye GG, Xue SF, Ma W, Jiang MQ, Ling Z, Tong XH, Dai LH (2012) Cutting AISI 1045 steel at very high speeds. Int J Mach Tools Manuf 56(0):1-9. https://doi.org/10.1016/j.ijmachtools. 2011.12.009

18. Molnar TG, Berezvai S, Kiss AK, Bachrathy D, Stepan G (2019) Experimental investigation of dynamic chip formation in orthogonal cutting. Int J Mach Tools Manuf 145:103429. https://doi.org/10. 1016/j.jimachtools.2019.103429

19. Molinari A, Musquar C, Sutter G (2002) Adiabatic shear banding in high speed machining of Ti-6Al-4V: experiments and modeling. Int J Plast 18(4):443-459. https://doi.org/10.1016/s0749-6419(01) 00003-1

20. Ye GG, Xue SF, Jiang MQ, Tong XH, Dai LH (2013) Modeling periodic adiabatic shear band evolution during high speed machining Ti-6Al-4V alloy. Int J Plast 40(0):39-55. https://doi.org/10. 1016/j.ijplas.2012.07.001

21. Sutter G, List G (2013) Very high speed cutting of Ti-6Al-4V titanium alloy - change in morphology and mechanism of chip formation. Int J Mach Tools Manuf 66(0):37-43. https://doi.org/ 10.1016/j.ijmachtools.2012.11.004

22. Ye GG, Chen Y, Xue SF, Dai LH (2014) Critical cutting speed for onset of serrated chip flow in high speed machining. Int J Mach Tools Manuf 86(0):18-33. https://doi.org/10.1016/j.ijmachtools. 2014.06.006

23. Cai SL, Dai LH (2014) Suppression of repeated adiabatic shear banding by dynamic large strain extrusion machining. J Mech Phys Solids 73(0):84-102. https://doi.org/10.1016/j.jmps.2014.09. 004
24. Liu Y, Cai S, Shang X, Dai L (2017) Suppression of Hopf bifurcation in metal cutting by extrusion machining. Nonlinear Dyn 88(1): 433-453. https://doi.org/10.1007/s11071-016-3251-x

25. Guo Y, Compton WD, Chandrasekar S (2015) In situ analysis of flow dynamics and deformation fields in cutting and sliding of metals. Proc R Soc A Math Phys Eng Sci 471(2178):20150194. https://doi.org/10.1098/rspa.2015.0194

26. Yeung H, Viswanathan K, Udupa A, Mahato A, Chandrasekar S (2017) Sinuous flow in cutting of metals. Phys Rev Appl 8(5): 054044. https://doi.org/10.1103/PhysRevApplied.8.054044

27. Mohammed WM, Ng E, Elbestawi MA (2011) Modeling the effect of the microstructure of compacted graphite iron on chip formation. Int J Mach Tools Manuf 51(10):753-765. https://doi.org/10.1016/j. ijmachtools.2011.06.005

28. Lee WB, Wang H, Chan CY, To S (2013) Finite element modelling of shear angle and cutting force variation induced by material anisotropy in ultra-precision diamond turning. Int $\mathrm{J}$ Mach Tools Manuf 75:82-86. https://doi.org/10.1016/j.ijmachtools.2013.09. 007

29. Rahman MA, Rahman M, Kumar AS (2017) Modelling of flow stress by correlating the material grain size and chip thickness in ultra-precision machining. Int J Mach Tools Manuf 123:57-75. https://doi.org/10.1016/j.ijmachtools.2017.08.001

30. Zhang W, Wang X, Hu Y, Wang S (2018) Predictive modelling of microstructure changes, micro-hardness and residual stress in machining of 304 austenitic stainless steel. Int J Mach Tools Manuf 130-131:36-48. https://doi.org/10.1016/j.ijmachtools.2018.03.008

31. Li C, Li X, Wu Y, Zhang F, Huang H (2019) Deformation mechanism and force modelling of the grinding of YAG single crystals. Int J Mach Tools Manuf 143:23-37. https://doi.org/10.1016/j. ijmachtools.2019.05.003

32. Ning J, Nguyen V, Huang Y, Hartwig KT, Liang SY (2018) Inverse determination of Johnson-Cook model constants of ultra-finegrained titanium based on chip formation model and iterative gradient search. Int J Adv Manuf Technol 99(5-8):1131-1140. https:// doi.org/10.1007/s00170-018-2508-6

33. Ning J, Nguyen V, Huang Y, Hartwig KT, Liang SY (2019) Constitutive modeling of ultra-fine-grained titanium flow stress for machining temperature prediction. Bio-Des Manuf 2(3):153160. https://doi.org/10.1007/s42242-019-00044-9

34. Ning J, Nguyen V, Liang SY (2019) Analytical modeling of machining forces of ultra-fine-grained titanium. Int J Adv Manuf Technol 101(1):627-636. https://doi.org/10.1007/s00170-0182889-6

35. Ning J, Liang SY (2019) A comparative study of analytical thermal models to predict the orthogonal cutting temperature of AISI 1045 steel. Int J Adv Manuf Technol 102(9):3109-3119. https://doi.org/ 10.1007/s00170-019-03415-9

36. Li XB, Jiang GM, Di JP, Yang Y, Wang CL (2020) Effect of cryogenic rolling on the microstructural evolution and mechanical properties of pure copper sheet. Mater Sci Eng A 772:138811. https://doi.org/10.1016/j.msea.2019.138811

37. Nag S, Sardar P, Jain A, Himanshu A, Mondal DK (2014) Correlation between ferrite grain size, microstructure and tensile properties of $0.17 \mathrm{wt} \%$ carbon steel with traces of microalloying elements. Mater Sci Eng A 597:253-263. https://doi.org/10.1016/j. msea.2013.12.073

38. Wan M, Wen D-Y, Ma Y-C, Zhang W-H (2019) On material separation and cutting force prediction in micro milling through involving the effect of dead metal zone. Int J Mach Tools Manuf 146: 103452. https://doi.org/10.1016/j.ijmachtools.2019.103452

39. Campbell CE, Bendersky LA, Boettinger WJ, Ivester R (2006) Microstructural characterization of Al-7075-T651 chips and work pieces produced by high-speed machining. Mater Sci Eng A Struct Mater Prop Microstruct Process 430(1-2):15-26. https://doi.org/10. 1016/j.msea.2006.04.122 
40. Geng X, Wang D, Deng J, Fanfan J, Zhufeng Y (2017) Simulation of the orthogonal cutting of OFHC copper based on the smoothed particle hydrodynamics method. Int J Adv Manuf Technol 91(1-4): 265-272. https://doi.org/10.1007/s00170-016-9723-9

41. Hodge AM, Furnish TA, Navid AA, Barbee TW (2011) Shear band formation and ductility in nanotwinned $\mathrm{Cu}$. Scr Mater 65(11): 1006-1009. https://doi.org/10.1016/j.scriptamat.2011.09.002

42. Wang YM, Ma E (2003) Temperature and strain rate effects on the strength and ductility of nanostructured copper. Appl Phys Lett 83(15):3165-3167. https://doi.org/10.1063/1.1618370

43. Matsushita M, Ohfuji $\mathrm{H}$ (2010) Analysis of the recrystallization of cold-rolled copper after isothermal annealing using electron backscattered diffraction patterns. Defect Diffus Forum 297-301: 359-364

44. Lu L, Chen X, Huang X, Lu K (2009) Revealing the maximum strength in nanotwinned copper. Science 323(5914):607-610. https://doi.org/10.1126/science.1167641

45. Lu L, You ZS, Lu K (2012) Work hardening of polycrystalline $\mathrm{Cu}$ with nanoscale twins. Scr Mater 66(11):837-842. https://doi.org/ 10.1016/j.scriptamat.2011.12.046

46. Mayer AE, Khishchenko KV, Levashov PR, Mayer PN (2013) Modeling of plasticity and fracture of metals at shock loading. J Appl Phys 113(19):193508. https://doi.org/10.1063/1.4805713

47. Merchant ME (1945) Mechanics of the metal cutting process. II. Plasticity conditions in orthogonal cutting. J Appl Phys 16(6):318324

48. Brown TL, Saldana C, Murthy TG, Mann JB, Guo Y, Allard LF, King AH, Compton WD, Trumble KP, Chandrasekar S (2009) A study of the interactive effects of strain, strain rate and temperature in LSEM of copper. Acta Mater 57(18):5491-5500. https://doi.org/ 10.1016/j.actamat.2009.07.052

49. Guo Y, Efe M, Moscoso W, Sagapuram D, Trumble KP, Chandrasekar S (2012) Deformation field in LSEM and implications for deformation processing. Scr Mater 66(5):235-238. https:// doi.org/10.1016/j.scriptamat.2011.10.045

50. Dao M, Lu L, Shen YF, Suresh S (2006) Strength, strain-rate sensitivity and ductility of copper with nanoscale twins. Acta Mater 54(20):5421-5432. https://doi.org/10.1016/j.actamat.2006.06.062

51. Frost HJ, Ashby MF (1982) Deformation-mechanism maps: the plasticity and creep of metals and ceramics. Pergamon Press, Oxford
52. Kittel C (2005) Introduction to solid state physics. Wiley, New York

53. Liu Y, Cai S, Xu F, Wang Y, Dai L (2019) Enhancing strength without compromising ductility in copper by combining extrusion machining and heat treatment. J Mater Process Technol 267:52-60. https://doi.org/10.1016/j.jmatprotec.2018.12.001

54. Christian JW, Mahajan S (1995) Deformation twinning. Prog Mater Sci 39(1-2):1-157

55. Malygin GA (1999) Dislocation self-organization processes and crystal plasticity. Physics-Uspekhi 42(9):887-916. https://doi.org/ 10.1070/pu1999v042n09abeh000563

56. Ding R, Guo ZX (2001) Coupled quantitative simulation of microstructural evolution and plastic flow during dynamic recrystallization. Acta Mater 49(16):3163-3175. https://doi.org/10.1016/ S1359-6454(01)00233-6

57. Meyers MA, Chawla KK (2009) Mechanical behavior of materials, 2nd edn. Cambridge University Press, Cambridge

58. De Chiffre L (1976) Extrusion-cutting. Int J Mach Tool Des Res 16(2):137-144. https://doi.org/10.1016/0020-7357(76)90032-9

59. Saldana C, Murthy TG, Shankar MR, Stach EA, Chandrasekar S (2009) Stabilizing nanostructured materials by coherent nanotwins and their grain boundary triple junction drag. Appl Phys Lett 94(2): 021910. https://doi.org/10.1063/1.3072595

60. Swaminathan S, Brown TL, Chandrasekar S, McNelley TR, Compton WD (2007) Severe plastic deformation of copper by machining: microstructure refinement and nanostructure evolution with strain. Scr Mater 56(12):1047-1050. https://doi.org/10.1016/ j.scriptamat.2007.02.034

61. Meyers MA, Mishra A, Benson DJ (2006) Mechanical properties of nanocrystalline materials. Prog Mater Sci 51(4):427-556. https:// doi.org/10.1016/j.pmatsci.2005.08.003

62. Lu L, Schwaiger R, Shan ZW, Dao M, Lu K, Suresh S (2005) Nano-sized twins induce high rate sensitivity of flow stress in pure copper. Acta Mater 53(7):2169-2179. https://doi.org/10.1016/j. actamat.2005.01.031

63. Lu L, Shen YF, Chen XH, Qian LH, Lu K (2004) Ultrahigh strength and high electrical conductivity in copper. Science 304(5669):422-426. https://doi.org/10.1126/science.1092905

Publisher's note Springer Nature remains neutral with regard to jurisdictional claims in published maps and institutional affiliations. 